\title{
Sialylation of immunoglobulin E is a determinant of allergic pathogenicity
}

https://doi.org/10.1038/s41586-020-2311-z

Received: 13 May 2019

Accepted: 11 March 2020

Published online: 20 May 2020

Check for updates
Kai-Ting C. Shade ${ }^{1,5}$, Michelle E. Conroy ${ }^{1,5}$, Nathaniel Washburn ${ }^{2}$, Maya Kitaoka', Daniel J. Huynh', Emma Laprise', Sarita U. Patil ${ }^{1,3,4}$, Wayne G. Shreffler ${ }^{1,3,4}$ \& Robert M. Anthony ${ }^{1 凶}$

Approximately one-third of the world's population suffers from allergies ${ }^{1}$. Exposure to allergens crosslinks immunoglobulin $\mathrm{E}$ (IgE) antibodies that are bound to mast cells and basophils, triggering the release of inflammatory mediators, including histamine ${ }^{2}$. Although IgE is absolutely required for allergies, it is not understood why total and allergen-specific IgE concentrations do not reproducibly correlate with allergic disease ${ }^{3-5}$. It is well-established that glycosylation of IgG dictates its effector function and has disease-specific patterns. However, whether IgE glycans differ in disease states or affect biological activity is completely unknown ${ }^{6}$. Here we perform an unbiased examination of glycosylation patterns of total IgE from individuals with a peanut allergy and from non-atopic individuals without allergies. Our analysis reveals an increase in sialic acid content on total IgE from individuals with a peanut allergy compared with non-atopic individuals. Removal of sialic acid from IgE attenuates effector-cell degranulation and anaphylaxis in several functional models of allergic disease. Therapeutic interventions-including removing sialic acid from cell-bound IgE with a neuraminidase enzyme targeted towards the IgE receptor FceRI, and administering asialylated IgE-markedly reduce anaphylaxis. Together, these results establish IgE glycosylation, and specifically sialylation, as an important regulator of allergic disease.
IgE antibodies bind to the surface of mast cells or basophils that express the high-affinity IgE receptor FceRI $\left(\right.$ ref. $^{2}$ ). Subsequent exposure to allergens crosslinks cell-bound IgE, leading to cellular activation and the release of allergic mediators, including histamine, prostaglandins and leukotrienes ${ }^{2}$. This cascade culminates in the canonical symptoms of allergic diseases, the most severe of which is anaphylaxis. Although IgE that recognizes otherwise innocuous allergens is well-established as the causative agent of most allergic diseases ${ }^{1,2}$, clinical allergy diagnostics remain relatively inaccurate ${ }^{3-5}$, and curative therapies, including oral immunotherapy, are cumbersome and only partially effective $\mathrm{e}^{7,8}$. Further, allergen-specific IgE is detected in many people who do not experience allergic symptoms ${ }^{3,5}$. Thus, while IgE is absolutely necessary for triggering the allergic cascade, it is not clear how IgE causes allergic disease in some circumstances and not others.

The composition of the glycans attached (via a single asparagine (N) residue) to immunoglobulin $\mathrm{G}$ markedly influences its biological activity, and affects the outcome of many diseases, including Dengue haemorrhagic fever ${ }^{9}$, Mycobacterium tuberculosis latency ${ }^{10}$, influenza vaccination ${ }^{11}$, rheumatoid arthritis ${ }^{6,12}$, and granulomatosis with polyangiitis ${ }^{13,14}$. There are seven $\mathrm{N}$-linked glycosylation sites distributed across the heavy chains of human IgE (hIgE) ${ }^{6,15}$. However, whether particular IgE glycans are associated with allergic diseases, or affect IgE function, is unknown. IgE is the least abundant antibody class in circulation, and, as such, analysis of hIgE glycosylation has been restricted to samples from individuals with myelomas, hyper-IgE syndromes, hyperimmune syndromes pooled from multiple donors, or recombinant $\operatorname{IgE}^{15-18}$. These studies revealed that there is a single $\mathrm{N}$-linked oligomannose glycan at N394 on IgE, that N383 is unoccupied, and that the remaining five sites are occupied by complex antennary glycans (Fig. 1a). Previously, the importance of glycans to IgE biology has been examined through treatment with glycosidases (enzymes that hydrolyse glycosidic bonds) $)^{17,19}$ and through mutation of glycosylation sites ${ }^{17,20}$. This revealed that the N394-linked oligomannose was required for appropriate IgE folding and FcERI binding ${ }^{17,20}$ to initiate effector functions.

Here we investigated whether allergic-disease-specific glycosylation patterns exist for IgE, and, if so, whether those patterns influence the biological activity of IgE. We characterized individuals as non-atopic if they reported no history of atopy, with low total IgE titres and little IgE reactivity to peanut allergen (Ara h 2), birch tree pollen allergen (Bet v1), house dust mite allergen (Der p 1) or cat allergen (Fel d 1) (Fig. 1b, c, Extended Data Fig. 1a and Extended Data Table 1). Individuals with a peanut allergy reported multiple atopies, had approximately twofold higher total IgE titres and reactivity to peanut allergen (Ara h 2) but not to other tested allergens, and were confirmed by clinician-supervised oral challenge (Fig. 1b, c, Extended Data Fig. 1a and Extended Data Table1) ${ }^{8}$.

${ }^{1}$ Center for Immunology and Inflammatory Diseases, Division of Rheumatology, Allergy and Immunology, Department of Medicine, Massachusetts General Hospital, Harvard Medical School, Boston, MA, USA. ${ }^{2}$ Momenta Pharmaceuticals Inc, Cambridge, MA, USA. ${ }^{3}$ Division of Pediatric Allergy and the MGH Food Allergy Center, Department of Pediatrics, Massachusetts General Hospital, Harvard Medical School, Boston, MA, USA. ${ }^{4}$ Food Allergy Science Initiative at the Broad Institute of the Massachusetts Institute of Technology and Harvard, Cambridge, MA, USA. ${ }^{5}$ These authors contributed equally: Kai-Ting C. Shade, Michelle E. Conroy. ${ }^{\bowtie}$ e-mail: robert.anthony@mgh.harvard.edu 

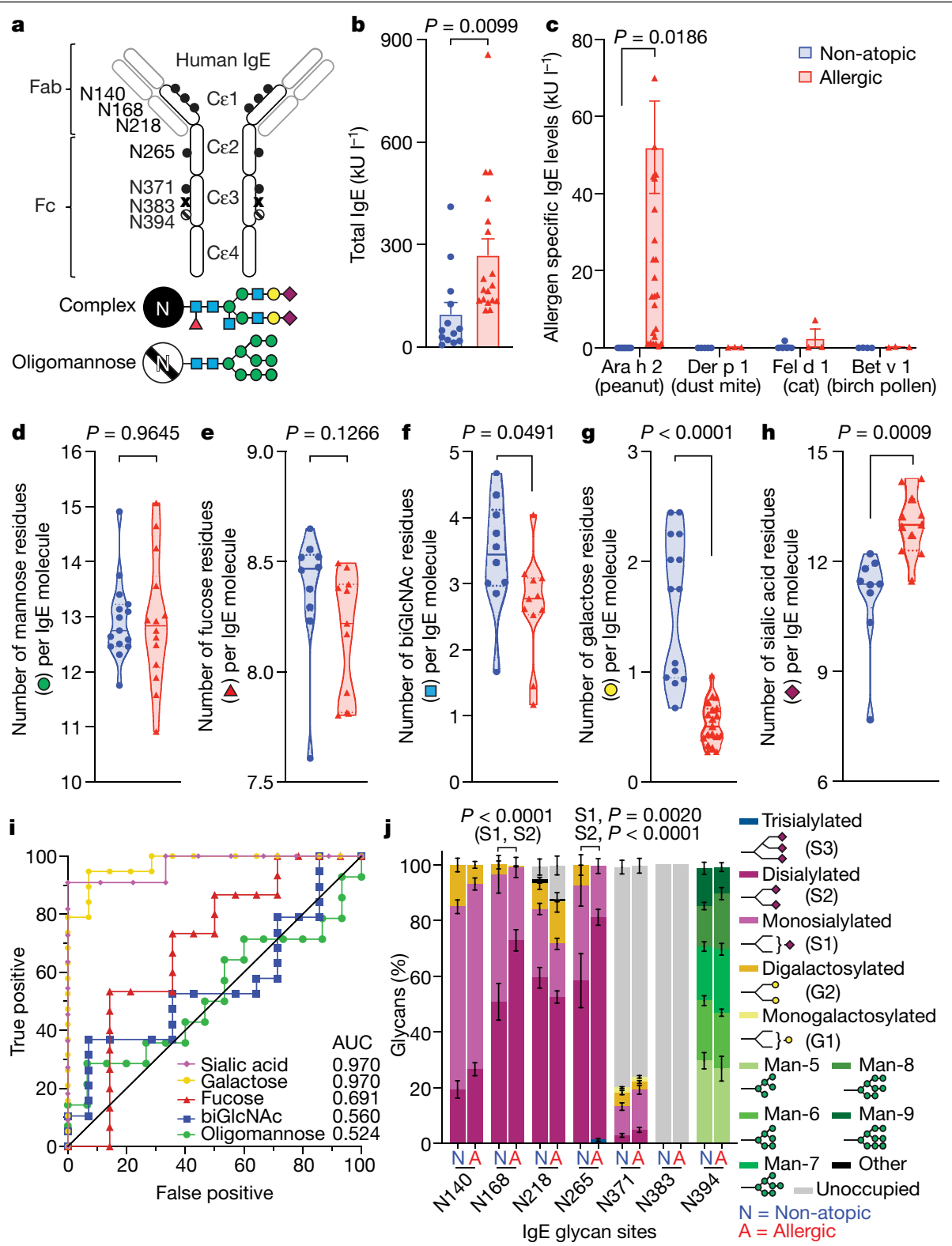

Fig. 1 Glycan composition of non-atopic and allergic IgE. a, Human IgE with the Fab and Fc domains, as well as $\mathrm{N}$-linked glycosylation sites, shown. Filled circles, complex biantennary glycans; hatched circles, oligomannose; $X$, unoccupied; blue squares, GlcNAc; green circles, mannose; red triangle, fucose; yellow circles, galactose; maroon diamonds, sialic acid. b, c, Total IgE titres (b) and allergen-specific IgE levels (c) in non-atopic individuals (blue, $n=17$ ) and individuals with allergies (red, $n=13$ ). d-h, Glycan moieties per IgE molecule, quantified by glycopeptide mass spectrometry (gMS), in non-atopic individuals (blue) and individuals with a peanut allergy (red): mannose (d; non-atopic, $n=15$; allergic, $n=14$ ); fucose (e; non-atopic, $n=10$; allergic, $n=11$ ); biGlcNAc (f; non-atopic, $n=10$; allergic, $n=11)$; galactose (g; non-atopic, $n=14$; allergic, $n=19)$; and sialic acid (h; non-atopic, $n=9$; allergic, $n=11)$. i, ROC for total IgE glycan moieties isolated from individuals with

We sensitized human LAD2 mast cells with similar amounts of total IgE enriched from the sera of these cohorts and activated the cells by anti-IgE crosslinking. We observed less degranulation-as measured by $\beta$-hexosaminidase release-in mast cells sensitized with IgE isolated from sera of non-atopic individuals compared with patients with a peanut allergy (Extended Data Fig. 1c), despite similar surface IgE loading (Extended Data Fig.1d, e). This suggested intrinsic functional differences between non-atopic and allergic IgE, independent of allergen specificity. allergies versus non-atopic individuals: sialic acid (non-atopic, $n=9$; allergic, $n=11$ ); galactose (non-atopic, $n=14$; allergic, $n=19$ ); fucose (non-atopic, $n=14$; allergic, $n=15$ ); biGlcNAc (non-atopic, $n=14$; allergic, $n=19$ ); and oligomannose (non-atopic, $n=15$; allergic, $n=14$ ). AUC, area under curve. $\mathbf{j}$, gMS analysis of site-specific $\mathrm{N}$-glycan structures on total IgE from non-atopic individuals (N140, $n=11 ; \mathrm{N} 168, n=13 ; \mathrm{N} 218, n=11 ; \mathrm{N} 265, \mathrm{~N} 371, \mathrm{~N} 394, n=12)$ and individuals with allergies (N140, $n=11 ; \mathrm{N} 168, n=15 ; \mathrm{N} 218, n=17 ; \mathrm{N} 265, n=18 ; \mathrm{N} 371, n=14$; $\mathrm{N} 394, n=12)$. Representative glycan structures per group are detailed in Extended Data Fig. 1h. Data shown are means \pm s.e.m. $(\mathbf{b}, \mathbf{c}, \mathbf{j})$, medians (solid lines) and interquartile ranges (dotted lines) (d-h); two-tailed unpaired $t$-test (b, d-h), two-way analysis of variance (ANOVA) with Sidak's (c) or Tukey's multiple comparison test (j).

Next, we analysed the N-glycans on total IgE enriched from these two cohorts by mass spectrometry ${ }^{16,18,21}$ (Extended Data Figs. 2,3). The mannose content on oligomannose moieties was similar between total non-atopic and allergic IgE (Fig. 1d). Fucose, $N$-acetyl glucosamine (GlcNAc), galactose and sialic acid can be attached to complex glycans (Fig. 1a). Although the total fucose content was similar between non-atopic and allergic IgE (Fig. 1e), substantially increased levels of bisecting GlcNAc (biGlcNAc) and terminal galactose were found on 

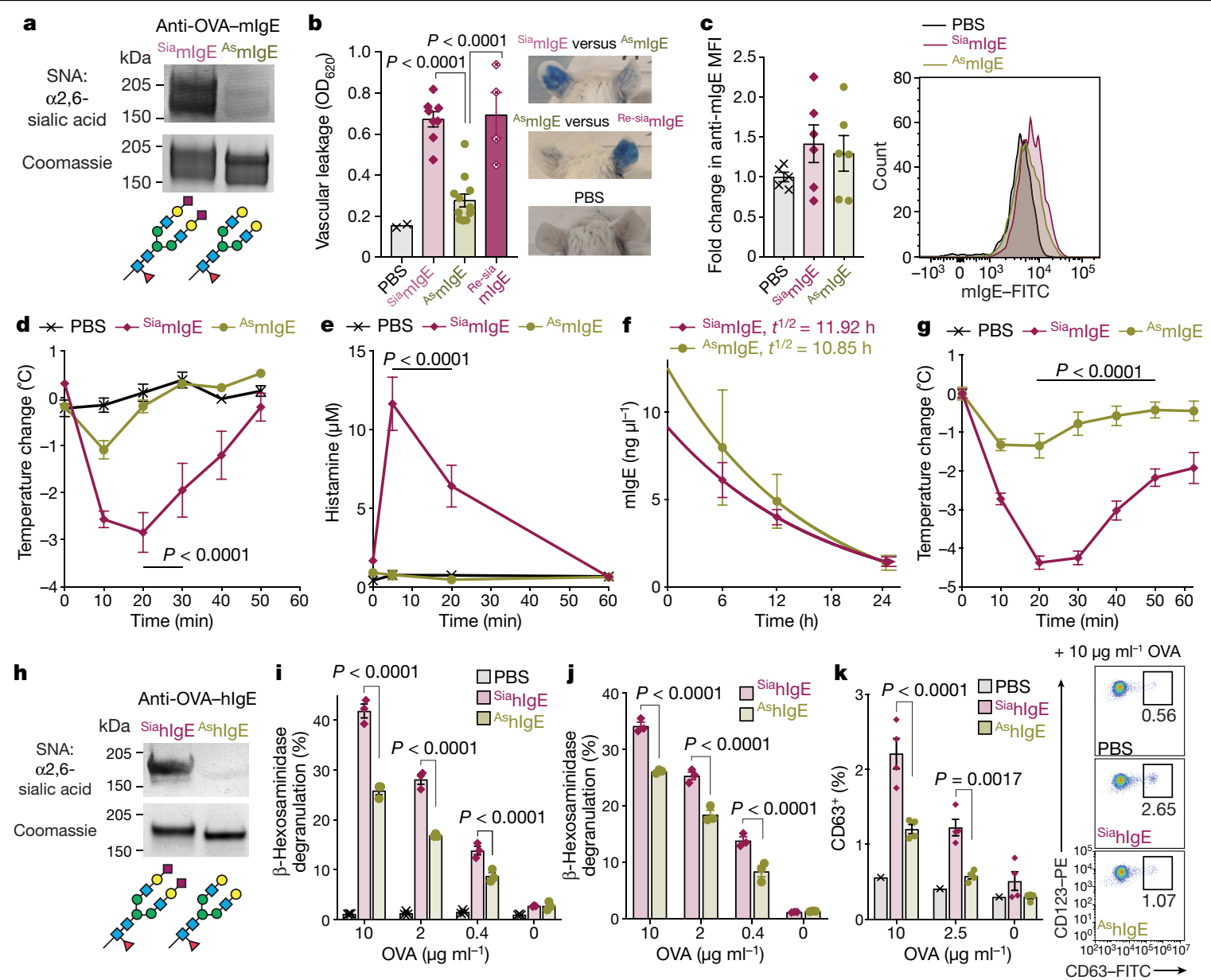

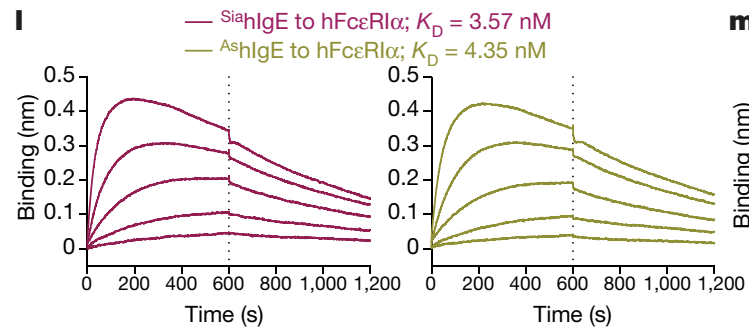

Fig. 2 Removal of sialic acid attenuates IgE. a, Blot for Sambucus nigra (SNA) lectin (top) and Coomassie-stained gel (bottom) of OVA-specific ${ }^{\mathrm{Sia}} \mathrm{mIgE}$ and ${ }^{A s} \mathrm{mIgE}$. b, Left, quantification of ear blue colouration, and right, representative ear images following OVA-induced PCA by PBS, OVA-specific ${ }^{\mathrm{Sia}} \mathrm{mIgE},{ }^{\mathrm{As}} \mathrm{mIgE}$ or ${ }_{\text {Re-Sia }} \mathrm{mIgE}\left(n=2,8,12\right.$ and 4 mouse ears respectively). $\mathrm{OD}_{620}$, optical density at $620 \mathrm{~nm}$. c, Left, mean fluorescence intensity (MFI), and right, representative histograms of anti-mIgE determined by fluorescence-activated cell sorting (FACS) on dermal mouse ear mast cells following sensitization with PBS, OVA-specific ${ }^{\mathrm{Sia}} \mathrm{mlgE}$ or ${ }^{\mathrm{As}} \mathrm{mlgE}(n=5,6$ and 6 mouse ears, respectively, from two independent experiments). FITC, fluorescein isothiocyanate.

d, e, Temperature change (d) and serum histamine levels (e) following DNP-induced PSA in mice sensitized with PBS, DNP-specific ${ }^{\text {Sia }} \mathrm{mIgE}$ or ${ }^{\mathrm{As}} \mathrm{mIgE}$ ( $n=3,5$ and 5 mice, respectively).f, Serum levels of DNP-specific ${ }^{\text {Sia }} \mathrm{mlgE}(n=4$ mice) or ${ }^{\mathrm{As}} \mathrm{mIgE}$ ( $n=5$ mice) after intraperitoneal administration. $g$,

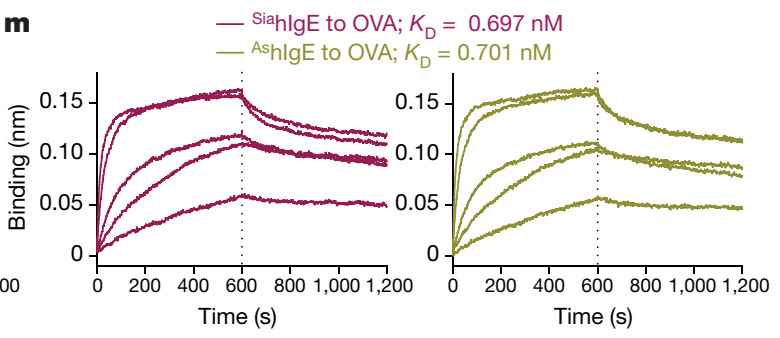

Temperature change following passive food anaphylaxis elicited by oral TNPOVA administration in mice sensitized with PBS, TNP-specific ${ }^{\text {Sia }} \mathrm{mIgE}^{\mathrm{As}}{ }^{\mathrm{As}} \mathrm{mIgE}$ ( $n=2,4$ and 4, respectively). h, SNA lectin blot and Coomassie-stained gel of OVA-specific ${ }^{\text {Sia }}$ hlgE and ${ }^{\text {As }}$ hIgE. i-k, OVA-induced degranulation in LAD2 mast cells (i), peripheral blood mononuclear cell derived human mast cells $(\mathbf{j})$ or basophils (k) sensitized with PBS (i, $n=3 ; \mathbf{k}, n=1)$, OVA-specific ${ }^{\text {SiahlgE }}$ or ${ }^{\text {As }}$ hlgE $(\mathbf{i}, n=3 ; \mathbf{j}, n=3 ; \mathbf{k}, n=4) . n$ is the number of technical replicates and is representative of three biologically independent experiments. PE, phycoerythrin. I, m, Binding kinetics of OVA-specific ${ }^{\text {Sia }}$ hlgE or ${ }^{\text {As }}$ hIgE to $\mathrm{hFceRI} \alpha(\mathbf{I})$ or OVA $(\mathbf{m}) . K_{\mathrm{D}}$, equilibrium dissociation constant. Data shown are means \pm s.e.m. $(\mathbf{b}-\mathbf{g}, \mathbf{i}-\mathbf{k})$ and are representative of two $(\mathbf{f})$ or three

$(\mathbf{a}, \mathbf{b}, \mathbf{d}, \mathbf{e}, \mathbf{g}-\mathbf{m})$ independent experiments. One-way ANOVA with Tukey's (b), or two-way ANOVA with Tukey's (d, e, i, k) or Sidak's (g, j) multiple comparison test. For gel source data, see Supplementary Fig.1. non-atopic IgE (Fig. 1f, g), whereas increased terminal sialylation was detected on allergic IgE (Fig. 1h).

To determine whether the glycan differences on total IgE were predictive of allergic disease, we assessed the variable glycan content on non-atopic and allergic IgE using receiver operating characteristics (ROC) curves (Fig. 1i). We found that the galactose and sialic acid contents of
IgE were uniquely strong predictors of allergic disease. Of note, differences in IgE sialylation were not sex- or age-dependent (Extended Data Fig. 1f, g). Glycosylation-site analysis showed that N140, N168, N265 and N394 of IgE were fully occupied by N-linked glycans, N218 and N371 were partially occupied ( $75 \%$ and $30 \%$ respectively), and $\mathrm{N} 383$ was completely unoccupied (Fig. 1j and Extended Data Fig. 4a), consistent with previous 

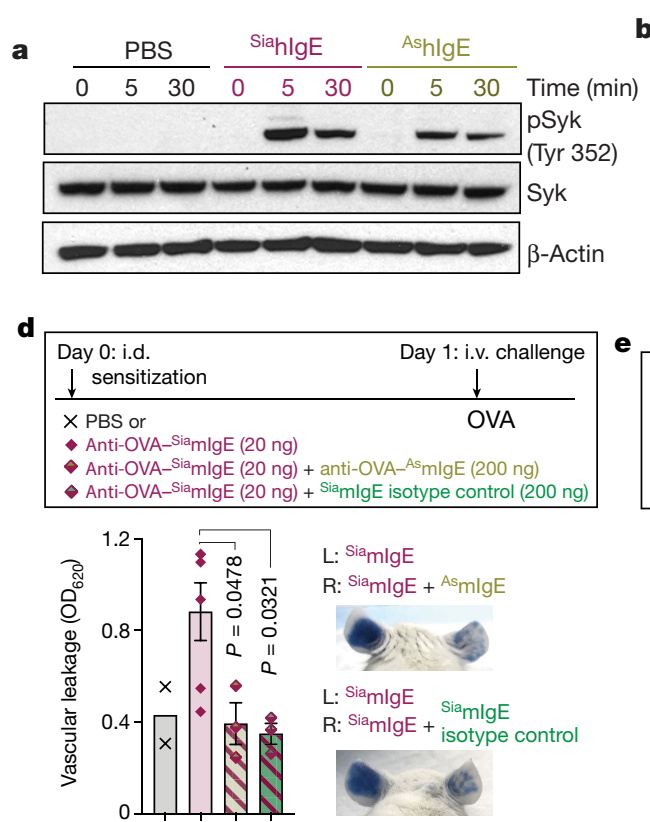

$\mathrm{PBS}+--$

SiamlgE - + + +

AsmlgE - - + Isotype ctrl

e

$\oplus$ Anti-OVA-SiahlgE + NEUFce b

- PBS — SiahlgE — AshlgE $+10 \mu \mathrm{g} \mathrm{ml}^{-1}$ OVA
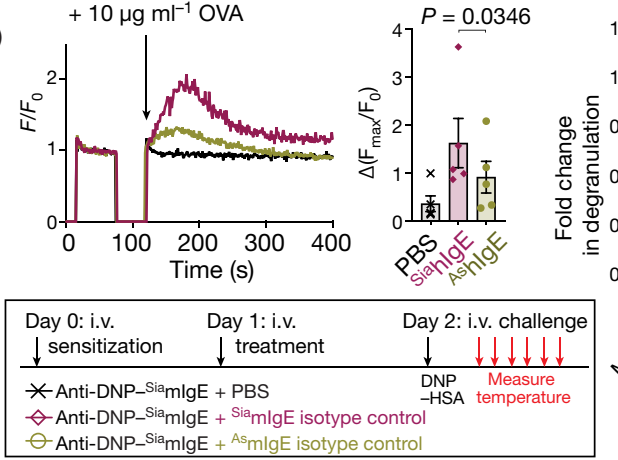

$\diamond$ Anti-OVA_SiahlgE + SiaFetuin - Anti-OVA-SianlgE + AsFetuin

1.2 + OVA
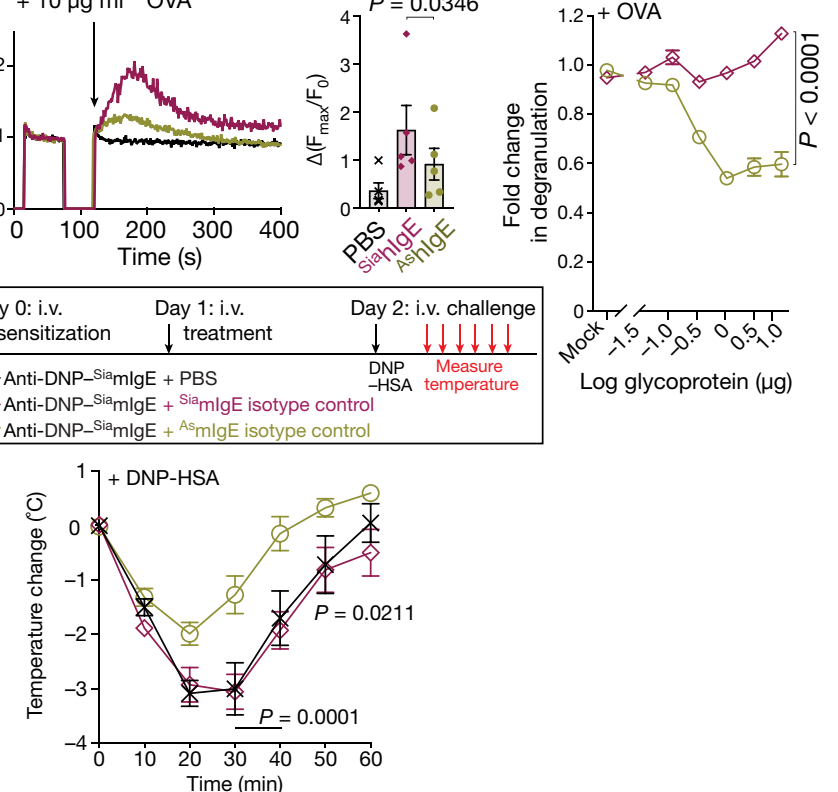

h

- Anti-OVA_SiahlgE + Isotype contro $\times$ Anti-OVA-SiahlgE + H-I NEUFo

$\leftrightarrow$ Peanut-allergic SiahlgE + NEUFCe

- Peanut-allergic SiahlgE + Isotype control * No IgE + NEUFce
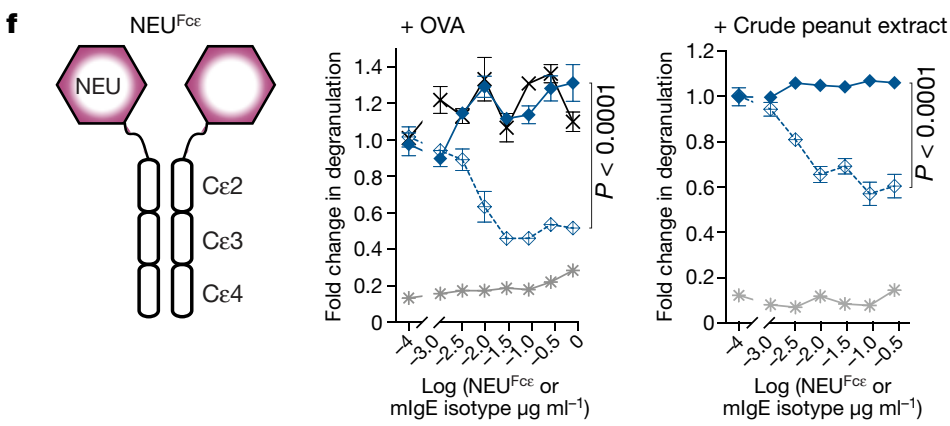
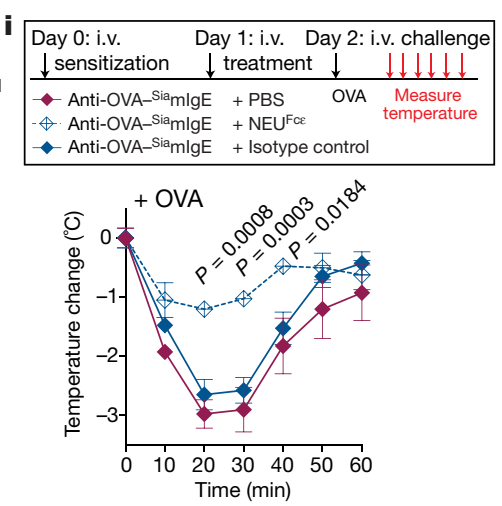

Fig. 3 | Modulating IgE sialylation and anaphylaxis. a, Immunoblots of phosphorylated (p)Syk, total Syk and $\beta$-actin in LAD2 mast cells sensitized with PBS, OVA-specific ${ }^{\text {Siah }}$ IgE or ${ }^{A s}$ hIgE after OVA stimulation.b, OVA-induced $\mathrm{Ca}^{2+}$ flux traces (left) and maximum values (right) in LAD2 cells sensitized with PBS

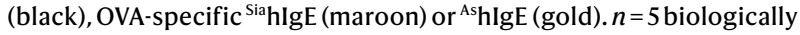
independent samples from three independent experiments. $F$, fluorescence ; $F_{0}$, fluorescence at time $0 ; F_{\max }$, maximum fluorescence.c, OVA-elicited degranulation in LAD2 cells sensitized with OVA-specific ${ }^{\text {Sia }}$ hIgE and treated

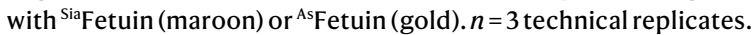
d, Quantification of ear blue colouration (bottom left) and representative images (bottom right) following OVA-induced PCA in mice sensitized with PBS, OVA-specific ${ }^{\mathrm{Sia}} \mathrm{mlgE}$, OVA-specific ${ }^{\text {Sia }} \mathrm{mIgE}$ plus OVA-specific ${ }^{\mathrm{As}} \mathrm{mIgE}$, or OVA-specific ${ }^{\mathrm{Sia}} \mathrm{mIgE}$ plus ${ }^{\mathrm{Sia}} \mathrm{mIgE}$ isotype control $(n=2,6,3$ and 3 mouse ears, respectively). Top, the experimental protocol; i.d., intradermal; i.v, intravenous.e, Temperature change following DNP-induced PSA in mice receiving DNP-specific ${ }^{\text {Sia }} \mathrm{mIgE}$ on day 0 and PBS, OVA-specific ${ }^{\text {Sia }} \mathrm{mIgE}$ or ${ }^{\mathrm{As}} \mathrm{mIgE}$ on day 1 ( $n=6,7$ and 7 , respectively, from two independent experiments). f, lllustration of $\mathrm{NEU}^{\mathrm{Fc} \varepsilon}$.g, OVA-induced degranulation in LAD2 cells sensitized with OVA-specific ${ }^{\text {Siah }}$ IgE or PBS and treated with $\mathrm{NEU}^{\mathrm{FC}}$, heat-inactivated $\mathrm{NEU}^{\mathrm{Fc \varepsilon}}\left(\mathrm{H}-\mathrm{INEU} \mathrm{N}^{\mathrm{Fc} \varepsilon}\right)$ or IgE isotype control.h, Peanut-induced degranulation in LAD2 cells sensitized with peanut-allergic ${ }^{\text {Sia }}$ hIgE or PBS and treated with $\mathrm{NEU}^{\mathrm{Fc} \varepsilon}$ or IgE isotype control. $\mathbf{g}, \mathbf{h}, n=3$ technical replicates. $\mathbf{i}$, Temperature changes following OVA-induced PSA in mice receiving OVA-specific ${ }^{\text {Sia }}{ }^{\mathrm{mIgE}}$ on day 0 and PBS, NEU ${ }^{\mathrm{Fc \varepsilon}}$ or IgE isotype control on day 1. $n=4$ mice per group. Data are means \pm s.e.m. $(\mathbf{b}-\mathbf{e}, \mathbf{g}-\mathbf{i})$ and are representative of two $(\mathbf{a}, \mathbf{d})$ and three $(\mathbf{c}, \mathbf{g}-\mathbf{i})$ independent experiments. Two-tailed paired $t$-test $(\mathbf{b})$, one-way ANOVA with Tukey's (d), or two-way ANOVA with Sidak's (c) or Tukey's multiple comparison test $(\mathbf{e}, \mathbf{g}-\mathbf{i})$. For gel source data, see Supplementary Fig. 1. results $^{15,16,18}$. N394-linked oligomannose structures (Fig. 1j and Extended Data Fig. 4b) and the N140-, N168-, N265- and N371-linked fucose and biGlcNAc contents (Fig. 1 j and Extended Data Fig. 4c, d) were similar between samples. However, N140- and N265-linked complex glycans terminating in galactose were enriched on non-atopic IgE, while terminal sialic acids, particularly disialylated glycans, were greatly enriched at N168 and N265 on allergic IgE (Fig. 1j and Extended Data Figs. 1h, 4e, f). Together, these results reveal that specific glycosylation patterns distinguish allergic from non-atopic total IgE.

Sialylation has been implicated in regulating several antibody classes, including the anti-inflammatory activity of IgG1 (ref. $\left.{ }^{22}\right)$, IgA-induced nephropathy and influenza neutralization ${ }^{23,24}$, and IgM-induced inhibitory signalling on $\mathrm{B}$ and $\mathrm{T}$ cells $\mathrm{s}^{25,26}$. We found that sialic acid is attached in $\alpha 2,6$ linkages on hIgE and mouse IgE (mIgE), as determined by neuraminidase (NEU) digestion assays and lectin blotting (Fig. 2a and Extended Data Fig. 5a-c), consistent with previous studies ${ }^{6,15,17}$. Thus, we treated mIgE with NEU and digestion buffer or with digestion buffer alone to generate mIgEs of identical allergen specificity that differed only in sialic acid content (Fig. 2a). In a model of passive cutaneous anaphylaxis (PCA), we sensitized mice with phosphate-buffered saline (PBS), ovalbumin (OVA)-specific sialylated mIgE ( $\left.{ }^{\mathrm{Sia}} \mathrm{mIgE}\right)$, or OVA-specific asialylated IgE $\left({ }^{\mathrm{As}} \mathrm{mIgE}\right)$ intradermally in the ears. The 
next day, we challenged the mice with allergen (OVA) in Evan's blue dye intravenously. Forty minutes after challenge, we quantified the amount of blue dye in the ear as a surrogate of histamine-mediated vascular leakage. PBS injection elicited little blue dye accumulation in the ear injection site, while substantial blue colouration was observed in ${ }^{\text {Sia }}$ mIgE-sensitized ears (Fig. 2b and Extended Data Fig. 5d). Notably, ${ }^{\text {As }}$ mIgE-sensitized ears exhibited markedly reduced blue colouration, indicative of attenuated anaphylaxis (Fig. $2 \mathrm{~b}$ and Extended Data Fig. 5d). To confirm that removal of sialic acid was responsible for reduced PCA reactivity, we reattached sialic acid to ${ }^{\mathrm{As}} \mathrm{mIgE}$ in vitro ( $\left.{ }^{\mathrm{Re}-\mathrm{sia}} \mathrm{mIgE}\right)$. ${ }^{\text {Re-sia }}$ mIgE triggered a robust PCA reaction (Fig. $2 \mathrm{~b}$ ), demonstrating that IgE sialylation affects the magnitude of anaphylaxis. Flow cytometry analysis of mast cells recovered from the mouse ears revealed no differences in IgE loading following sensitization with ${ }^{\text {Sia }} \mathrm{mIgE}$ or ${ }^{\mathrm{As}} \mathrm{mIgE}$ (Fig. 2c and Extended Data Fig. 5e), and that ${ }^{\mathrm{Sia}} \mathrm{mIgE}$ and ${ }^{\mathrm{As}} \mathrm{mIgE}$ bound allergen similarly, as determined by enzyme-linked immunosorbent assay (ELISA) (Extended Data Fig. 5f). Thus, the attenuation of cutaneous anaphylaxis by ${ }^{A s} \mathrm{mIgE}$ was independent of IgE loading on mast cells in vivo or allergen recognition.

Next, we systemically sensitized mice with ${ }^{\mathrm{Sia}} \mathrm{mIgE},{ }^{\mathrm{As}} \mathrm{mIgE}$ or PBS and challenged them with allergen the following day in a model of passive systemic anaphylaxis (PSA). ${ }^{\text {Sia }} \mathrm{mIgE}$-sensitized mice elicited a robust anaphylactic response underscored by a marked temperature loss 20 min after allergen challenge (Fig. 2d and Extended Data Fig. 5g, h). However, minimal temperature drop was observed in ${ }^{A s}$ mIgE- or PBS-sensitized mice (Fig. 2d and Extended Data Fig. 5g, h). Consistent with this, we detected a systemic increase in histamine in ${ }^{\mathrm{Sia}} \mathrm{mIgE}$-sensitized animals following challenge, but not in ${ }^{\mathrm{As}} \mathrm{mIgE}$ - or PBS-treated mice (Fig. 2e). Asialylated glycoproteins have a decreased serum half-life ${ }^{27}$, and we therefore compared the levels of ${ }^{\text {Sia }} \mathrm{mIgE}$ and ${ }^{\text {As }} \mathrm{mIgE}$ in circulation following systemic administration. However, sialic acid removal had little effect on IgE half-life (Fig. $2 \mathrm{f}$ and Extended Data Fig. 5i). To extend these findings to a model of passive food allergy, we sensitized mice systemically with $\mathrm{PBS},{ }^{\mathrm{Sia}} \mathrm{mIgE}$ or ${ }^{\mathrm{As}} \mathrm{mIgE}$, and challenged them with allergen orally the following day. Sensitization to ${ }^{\text {Sia }} \mathrm{mIgE}$, but not to ${ }^{\mathrm{As}} \mathrm{mIgE}$ or PBS, resulted in a marked temperature loss following oral allergen challenge (Fig. $2 \mathrm{~g}$ ).

We next asked whether sialylation similarly regulated hIgE, and sensitized human LAD2 mast cells with PBS or with sialylated or asialylated hIgE ( ${ }^{\text {SiahlgE or }}{ }^{\text {As }}$ hIgE, respectively; Fig. 2h). The cells were stimulated with allergen, and degranulation was quantified in $\beta$-hexosaminidase-release assays. ${ }^{\text {As }}$ hIgE-sensitized cells showed markedly reduced degranula-

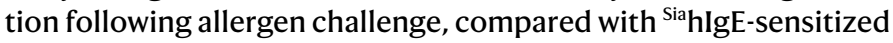
cells (Fig. 2i). We examined LAD2 mast cells after sensitization by flow cytometry, finding comparable hIgE loading following ${ }^{\text {Sia }}$ hIgE or ${ }^{\text {As }}$ hIgE sensitization (Extended Data Fig. 6a). Similar findings were observed in human mast cells derived from primary peripheral blood $\mathrm{CD} 4^{+}$cell culture, where ${ }^{\mathrm{As}}$ hIgE-sensitized cells had markedly reduced

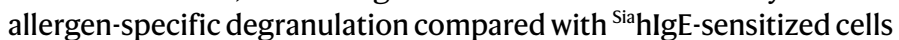
(Fig. $2 \mathrm{j}$ and Extended Data Fig. 6b). In parallel, we sensitized primary basophils with PBS, ${ }^{\text {Sia }}$ hlgE and ${ }^{\text {As }}$ hIgE and stimulated them with allergen (Extended Data Fig. 6c). ${ }^{\text {As }}$ hIgE-sensitized basophils elicited reduced degranulation after allergen stimulation-as measured by surface staining of the granule marker CD63-compared with basophils sensitized

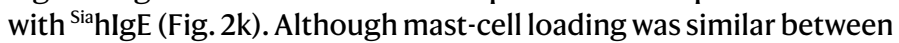
mouse and human ${ }^{\text {Sia } I g E ~ a n d ~}{ }^{\text {As }}$ IgE (Fig. 2c and Extended Data Fig. 6a), we investigated whether sialylation altered the kinetics of hIgE binding to its receptor, FceRI. Biolayer interferometry (BLI) assays revealed no difference in ${ }^{\text {SiahlgE and }}{ }^{\text {As }}$ hlgE interactions with FceRI (Fig. 2l). Sialylation also did not alter IgE binding to the allergen (Fig. $2 \mathrm{~m}$ ). Thus, removing sialic acid from IgE attenuates its effector functions in vivo and in vitro, while binding to allergen, mast cells and FceRI remains intact.

Because sialylation does not alter IgE interactions with allergen and receptor, we examined whether signalling downstream of FceRI is affected. LAD2 mast cells sensitized with ${ }^{\text {Sia }}$ IIgE or ${ }^{\text {As }}$ hIgE were stimulated with allergen, and cellular lysates were collected at defined intervals. Western blotting of mast-cell lysates for the tyrosine kinase Syk revealed reduced phosphorylation in cells sensitized with ${ }^{\mathrm{As}} \mathrm{hIgE}$ at $5 \mathrm{~min}$ and $30 \mathrm{~min}$ after stimulation (Fig. 3a). Similarly, calcium flux was reduced in ${ }^{A s}$ hIgE-sensitized LAD2 mast cells following allergen

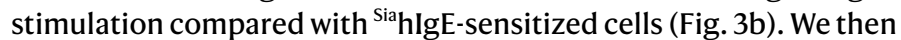
asked whether a surrogate asialylated glycoprotein could attenuate anaphylaxis similarly to asialylated IgE. LAD2 mast cells were sensitized

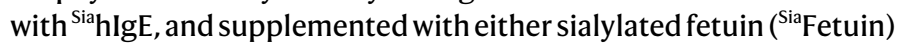
or asialylated fetuin ( ${ }^{\text {As }}$ Fetuin) (Extended Data Fig. 5b). Quantifying allergen-specific degranulation revealed that addition of sialylated fetuin had no effect, while asialylated fetuin inhibited allergen-induced mast-cell degranulation (Fig. $3 \mathrm{c}$ ). Together, these results suggest that removal of sialic acid exposes an inhibitory glycan that dampens FceRI signalling.

These observations indicated that ${ }^{\mathrm{As}}$ IgE can actively inhibit anaphylaxis in vivo. We therefore sensitized mice intradermally in the ears with PBS, OVA-specific ${ }^{\text {Sia }} \mathrm{mIgE}$, a combination of OVA-specific ${ }^{\text {Sia }} \mathrm{mIgE}$ and tenfold more OVA-specific ${ }^{\mathrm{As}} \mathrm{mIgE}$, or a combination of OVA-specific ${ }^{\text {Sia }}$ mIgE and tenfold more trinitrophenyl (TNP)-specific ${ }^{\text {Sia }} \mathrm{mIgE}$ isotype control. The next day we challenged mice with OVA, and quantified blue colouration of the ears. Extensive vascular leakage occurred in ears sensitized with OVA-specific ${ }^{\text {Sia }} \mathrm{mIgE}$ alone (Fig. 3d). However, co-sensitization of OVA-specific ${ }^{\text {Sia }} \mathrm{mIgE}$ with either OVA-specific ${ }^{\mathrm{As}} \mathrm{mIgE}$ or TNP-specific ${ }^{\mathrm{Sia}} \mathrm{mIgE}$ both resulted in greatly reduced vascular leakage (Fig. 3d). Next, we systematically sensitized mice with 2,4-dinitrophenyl (DNP)-specific ${ }^{\mathrm{Sia}} \mathrm{mIgE}$ on day 0 , and then PBS, OVA-specific ${ }^{\text {Sia }} \mathrm{mIgE}$ or OVA-specific ${ }^{A s} \mathrm{mIgE}$ on day 1 , finally challenging them with DNP conjugated to human serum albumin (HSA) on day 2. Mice that were sensitized with DNP-specific ${ }^{\text {Sia }}$ mIgE on day 0 and PBS or OVA-specific ${ }^{\text {Sia }}$ mIgE on day 1 exhibited a robust temperature loss after allergen challenge. However, DNP-specific ${ }^{\text {Sia }}$ mIgE-sensitized mice that received OVA-specific ${ }^{\mathrm{As}} \mathrm{mIgE}$ on day 1 had a greatly attenuated temperature loss upon allergen challenge (Fig. 3e). Systemic challenge of these treatment groups with OVA revealed that only sensitization with OVA-specific ${ }^{\text {Sia }}$ mIgE resulted in a temperature drop, while all other groups were unaffected (Extended Data Fig. 7a). These results suggest that ${ }^{\mathrm{As}}$ mIgE attenuates anaphylaxis by occupying FceRI, but can actively dampen systemic anaphylaxis.

As removal of sialic acid attenuates IgE effector functions, we explored whether targeting sialic acid on IgE-bearing cells represents a viable strategy for attenuating allergic inflammation. Thus, we genetically fused a neuraminidase to the $\mathrm{N}$ terminus of IgE Fc CE2-4 domains (NEU ${ }^{\mathrm{Fc}}$; Fig. 3f and Extended Data Fig. 7b) to direct sialic acid removal specifically to IgE-bearing cells. This fusion protein retained binding to FceRI (Extended Data Fig. 7c), could be loaded on mast cells (Extended Data Fig. 7d), and had neuraminidase activity (Extended Data Fig. 7e-h). We sensitized LAD2 mast cells with OVA-specific ${ }^{\text {Sia }}$ hIgE, incubated them briefly with increasing concentrations of $\mathrm{NEU}^{\mathrm{FC \varepsilon}}$, heat-inactivated $\mathrm{NEU}^{\mathrm{Fc \varepsilon}}$, or an IgE isotype to control for FceRI occupancy, and stimulated them with OVA. Treatment with NEU ${ }^{\mathrm{Fc \varepsilon}}$, but not with heat-inactivated $\mathrm{NEU}^{\mathrm{FCE}}$ or the isotype control, attenuated OVA-induced degranulation in a dose-dependent manner (Fig. $3 \mathrm{~g}$ ). To extend our findings to allergic hIgE from patients with a peanut allergy, we sensitized LAD2 mast cells with peanut-allergic ${ }^{\text {Sia }}$ hIgE and treated them with $N U^{\mathrm{Fc \varepsilon}}$ or with an IgE isotype control. Consistently, allergen-induced degranulation was markedly attenuated by $\mathrm{NEU}^{\mathrm{Fc} \varepsilon}$ treatment of peanut-allergic SiahIgE-sensitized cells compared with IgE isotype control treatment (Fig. 3h). Unsensitized LAD2 mast cells treated with NEU ${ }^{\mathrm{Fc \varepsilon}}$ did not degranulate ('No IgE plus NEU ${ }^{\mathrm{FcE}} ; \mathrm{Fig} .3 \mathrm{~g}$, h), indicating that NEU ${ }^{\mathrm{Fc} \varepsilon}$ treatment does not stimulate mast cells. We next explored the therapeutic potential of modulating sialic acid content in vivo. Mice were sensitized systemically with ${ }^{\text {Sia }}$ mIgE on day 0 , and treated with PBS, NEU ${ }^{\mathrm{Fc \varepsilon}}$ or IgE isotype control on day 1 . The following day, the mice were challenged systemically with allergen, and core body temperature 


\section{Article}

was measured. ${ }^{\text {Sia }}$ mIgE-sensitized mice that received PBS or isotype control exhibited robust drops in temperature (Fig. 3i). NEU ${ }^{\mathrm{Fc \varepsilon}}$ treatment markedly attenuated the allergen-induced temperature drop (Fig. 3i), providing evidence of the therapeutic potential of targeting sialic acid on IgE-bearing cells.

IgE-mediated allergic diseases are multifactorial, with a broad range of clinical presentations, and paradoxically many individuals produce allergen-specific IgE without manifestation of disease. Further, there is a high rate of false-positive test results for food allergens ${ }^{3,5,8,28}$. Many non-mutually exclusive mechanisms for this discrepancy exist, including differences in IgE affinity or epitope diversity for allergens, mast-cell numbers, FceRI expression levels, Syk signalling, allergen-specific IgG antibodies, anti-IgE antibodies, and numbers of regulatory T cells ${ }^{29}$. Here we have shown that the sialic acid content on total IgE distinguishes peanut-allergic and non-atopic IgE. Further, we have found that allergic reactions are attenuated by removing sialic acid from IgE or administering asialylated glycoproteins. Although the sialic acid content of IgE and its role in other contexts is unknown, we propose that sialylation is an additional factor that regulates its biology. Thus, exploitation of the IgEsialylation axis presents a compelling diagnostic and therapeutic strategy.

\section{Online content}

Any methods, additional references, Nature Research reporting summaries, source data, extended data, supplementary information, acknowledgements, peer review information; details of author contributions and competing interests; and statements of data and code availability are available at https://doi.org/10.1038/s41586-020-2311-z.

1. Gupta, R. S. et al. Prevalence and severity of food allergies among US adults. JAMA Netw. Open 2, e185630 (2019)

2. Gould, H. J. \& Sutton, B. J. IgE in allergy and asthma today. Nat. Rev. Immunol. 8, 205-217 (2008)

3. Bird, J. A., Crain, M. \& Varshney, P. Food allergen panel testing often results in misdiagnosis of food allergy. J. Pediatr. 166, 97-100 (2015)

4. Du Toit, G. et al. Randomized trial of peanut consumption in infants at risk for peanut allergy. N. Engl. J. Med. 372, 803-813 (2015).

5. Peters, R. L., Gurrin, L. C. \& Allen, K. J. The predictive value of skin prick testing for challenge-proven food allergy: a systematic review. Pediatr. Allergy Immunol. 23 , 347-352 (2012).

6. Arnold, J. N., Wormald, M. R., Sim, R. B., Rudd, P. M. \& Dwek, R. A. The impact of glycosylation on the biological function and structure of human immunoglobulins. Annu. Rev. Immunol. 25, 21-50 (2007).
7. Bégin, P. et al. Phase 1 results of safety and tolerability in a rush oral immunotherapy protocol to multiple foods using omalizumab. Allergy Asthma Clin. Immunol. 10, 7 (2014).

8. Patil, S. U. et al. Peanut oral immunotherapy transiently expands circulating Ara $\mathrm{h}$ 2-specific B cells with a homologous repertoire in unrelated subjects. J. Allergy Clin. Immunol. 136, 125-134 (2015).

9. Wang, T. T. et al. IgG antibodies to dengue enhanced for FcyRIIIA binding determine disease severity. Science 355, 395-398 (2017).

10. Lu, L. L. et al. A functional role for antibodies in tuberculosis. Cell 167, 433-443 (2016)

11. Wang, T. T. et al. Anti-HA glycoforms drive B cell affinity selection and determine influenza vaccine efficacy. Cell 162, 160-169 (2015).

12. Parekh, R. B. et al. Association of rheumatoid arthritis and primary osteoarthritis with changes in the glycosylation pattern of total serum IgG. Nature 316, 452-457 (1985).

13. Espy, C. et al. Sialylation levels of anti-proteinase 3 antibodies are associated with the activity of granulomatosis with polyangiitis (Wegener's). Arthritis Rheum. 63, 2105-2115 (2011).

14. Wang, T. T. \& Ravetch, J. V. Functional diversification of IgGs through Fc glycosylation. J. Clin. Invest. 129, 3492-3498 (2019).

15. Arnold, J. N. et al. The glycosylation of human serum IgD and IgE and the accessibility of identified oligomannose structures for interaction with mannan-binding lectin. J. Immunol. 173, 6831-6840 (2004).

16. Plomp, R. et al. Site-specific N-glycosylation analysis of human immunoglobulin $\mathrm{E}$. J. Proteome Res. 13, 536-546 (2014).

17. Shade, K. T. et al. A single glycan on $\mathrm{IgE}$ is indispensable for initiation of anaphylaxis. J. Exp. Med. 212, 457-467 (2015).

18. Wu, G. et al. Glycoproteomic studies of IgE from a novel hyper IgE syndrome linked to PGM3 mutation. Glycoconj. J. 33, 447-456 (2016).

19. Yamazaki, T. et al. Receptor-destroying enzyme (RDE) from Vibrio cholerae modulates IgE activity and reduces the initiation of anaphylaxis. J. Biol. Chem. 294, 6659-6669 (2019).

20. Jabs, F. et al. Trapping IgE in a closed conformation by mimicking CD23 binding prevents and disrupts FceRl interaction. Nat. Commun. 9, 7 (2018).

21. Wuhrer, M. et al. Glycosylation profiling of immunoglobulin $\mathrm{G}(\lg G)$ subclasses from human serum. Proteomics 7, 4070-4081 (2007).

22. Nimmerjahn, F. \& Ravetch, J. V. Anti-inflammatory actions of intravenous immunoglobulin. Annu. Rev. Immunol. 26, 513-533 (2008).

23. Ding, J. X. et al. Aberrant sialylation of serum IgA1 was associated with prognosis of patients with IgA nephropathy. Clin. Immunol. 125, 268-274 (2007).

24. Maurer, M. A. et al. Glycosylation of human IgA directly inhibits influenza A and other sialic-acid-binding viruses. Cell Rep. 23, 90-99 (2018).

25. Colucci, $\mathrm{M}$. et al. Sialylation of $\mathrm{N}$-linked glycans influences the immunomodulatory effects of IgM on T cells. J. Immunol. 194, 151-157 (2015).

26. Collins, B. E., Smith, B. A., Bengtson, P. \& Paulson, J. C. Ablation of CD22 in ligand-deficient mice restores $B$ cell receptor signaling. Nat. Immunol. 7, 199-206 (2006).

27. Abe, K., Yamamoto, K. \& Sinohara, H. Clearance of desialylated mouse alpha-macroglobulin and murinoglobulin in the mouse. J. Biochem. 108, 726-729 (1990).

28. Fleischer, D. M. et al. Oral food challenges in children with a diagnosis of food allergy. J. Pediatr. 158, 578-583 (2011).

29. Sampath, V. et al. Deciphering the black box of food allergy mechanisms. Ann. Allergy Asthma Immunol. 118, 21-27 (2017).

Publisher's note Springer Nature remains neutral with regard to jurisdictional claims in published maps and institutional affiliations.

(c) The Author(s), under exclusive licence to Springer Nature Limited 2020 


\section{Methods}

\section{IgE antibodies}

All human samples were collected under Institutional Review Board (IRB)-approved protocols by Massachusetts General Hospital (MGH) and Research Blood Components, including informed consent obtained in accordance with relevant ethical regulations. Serum samples were obtained from individuals with a peanut allergy before treatment. Peanut allergy was confirmed by clinical history, allergen-specific IgE screening and double-blind placebo-controlled oral challenge (trial number NCT01750879/PNOIT2) ${ }^{8}$ (Extended Data Table 1). Non-atopic adults were recruited on the basis of self-identification as non-allergic donors. Non-atopy was confirmed by clinical history and allergen-specific IgE screening (Extended Data Table 1). Total IgE, Ara h 2-specific IgE, Fel d 1-specific IgE, Der p 1-specific IgE, and Bet v 1-specific IgE were determined by ImmunoCap Assay (Phalleon, Thermo Scientific) according to the manufacturer's protocols. Primary IgE was enriched from serum samples by serially depleting IgG using protein $\mathrm{G}$ agarose (GE Healthcare) followed by anti-IgE conjugated $N$-hydroxysuccinimide (NHS) beads (GE Healthcare). IgE purity was confirmed by protein electrophoresis and Coomassie gel staining. Recombinant OVA-specific IgE was generated as described ${ }^{17}$. In brief, complementary DNA sequences for generating OVA-specific heavy $(\varepsilon)$ and light $(\mathrm{K})$ chains of mouse and human $\operatorname{Ig} \mathrm{E}^{17}$ were cloned into plasmid pcDNA3.4 using restriction-enzyme sites $X b a$ I and Agel. To generate recombinant OVA-specific mouse or human IgE, plasmids containing OVA-specific heavy and light chains were transiently co-transfected at a 1:1 ratio using an Expi293 Expression System Kit (Life Technologies) according to the manufacturer's protocol. Cells expressing IgE were selected by adding $400 \mathrm{\mu g} \mathrm{ml}^{-1}$ of the antibiotic $\mathrm{G} 418$ to the culture medium for two weeks, and maintained before expanding to a larger-scale production. OVA-specific IgE was purified from cell culture supernatant using OVA-coupled agarose beads ${ }^{17}$.

\section{ELISA}

Sandwich ELISA for quantifying mIgE and OVA-specific binding was conducted as described ${ }^{17}$. In brief, 96-well Nunc plates were coated with goat polyclonal anti-mouse IgE (Bethyl Laboratories) or OVA, and blocked with bovine serum albumin (BSA) in PBS (1\% BSA for mIgE and $2 \%$ for OVA) before sample incubation. Samples were probed with goat polyclonal anti-mouse IgE conjugated to horseradish peroxidase (HRP; $2 \mathrm{ng} \mathrm{ml}^{-1}$; Bethyl Laboratories). The reactions were detected using 3,3,5,5-tetramethylbenzidine (TMB; Thermo Fisher Scientific) and stopped with $2 \mathrm{M}$ sulfuric acid; absorbance was measured at $450 \mathrm{~nm}$.

\section{gMS and glycopeptide analysis}

We quantified the site-specific glycosylation of IgE isolated from non-allergic donors and from donors with a peanut allergy by using nanoscale liquid chromatography with tandem mass spectrometry (LC-MS/MS) following enzymatic digestion of the proteins as described previously, with minor modifications ${ }^{16-18}$ (Extended Data Table 2). Isolated polyclonal primary hIgE and myeloma hIgE (Sigma Aldrich catalogue number AG30P) were prepared for proteolysis by denaturing the protein in $6 \mathrm{M}$ guanidine $\mathrm{HCl}$, followed by reduction with dithiothreitol, alkylation with iodoacetamide, and dialysis into $25 \mathrm{mM}$ ammonium bicarbonate $(\mathrm{pH} 7.8)$. Proteolysis was carried out with either trypsin to quantify N218, N371 and N394, or chymotrypsin to quantify N140, N168 and N265. For the tryptic digest, IgE was incubated with trypsin (Trypsin Gold Promega) at a 1:50 enzyme-to-substrate ratio overnight at $37^{\circ} \mathrm{C}$. For the chymotryptic digest, IgE was incubated with chymotrypsin (Sequencing Grade Promega) at a 1:100 enzyme-to-substrate ratio for $4 \mathrm{~h}$ at $25^{\circ} \mathrm{C}$. Both enzymes were quenched with formic acid added to $2 \% \mathrm{w} / \mathrm{w}$. The separation was performed on a Thermo EasySpray $\mathrm{C} 18 \mathrm{nLC}$ column $(0.75 \mu \mathrm{m} \times 50 \mathrm{~cm})$ using water and acetonitrile with $0.1 \%$ formic acid for mobile phase A and mobile phase B, respectively.
A linear gradient from $1 \%$ to $35 \%$ mobile phase $B$ was run over $75 \mathrm{~min}$. Mass spectra were recorded on a Thermo Q Exactive mass spectrometer operated in positive mode using data-independent acquisition (DIA), targeting the masses shown in Extended Data Table 2. Glycopeptides were quantified on the basis of the extracted ion area of the Y1 ion (Extended Data Fig. 2). Relative abundances were calculated for all identified glycan species for each site. Myeloma IgE (Sigma Aldrich catalogue number AG30P) was run before paired sample sets to monitor retention-time shifts and to ensure consistency in the analytical results across the sample set. The number of sugar residues per site per IgE molecule was calculated using the relative abundance of each glycan. For example, if we determined a particular site to have $60 \%$ monosialylated and fucosylated glycans (A1F) and $40 \%$ of disialylated and fucosylated glycans (A2F), then the number of sialic acids at one site would be $1.4((0.6 \times 1)+(0.4 \times 2))$, with a total of 2.8 sialic acids per molecule (accounting for two sites).

\section{Generation of NEU ${ }^{\mathrm{Fc} \varepsilon}$}

We designed the neuraminidase fusion protein by fusing a $\mathrm{k}$ light chain secretion signal sequence to the sialidase gene from Arthrobacter urefaciens (EC 3.2.1.18, gene AU104) ${ }^{30}$. The stop codon of AU104 was omitted; instead, a short flexible linker peptide (GGGGGG), the mouse IgE C 2 , $\mathrm{C} \varepsilon 3$ and $\mathrm{C} \varepsilon 4$ domains, and $6 \times$ histidine tag were inserted into the carboxy terminus of the sialidase. The gene was codon-optimized for humans and synthesized by GenScript. The 288-kDa protein was then produced by WuXi biologics. Sialidase activity of $\mathrm{NEU}^{\mathrm{Fc \varepsilon}}$ was determined by the level of $p$-nitrophenol released from $250 \mu \mathrm{M} 2-O$-( $p$-nitrophenyl)$\alpha$-D- $N$-acetylneuraminic acid (Sigma) in $100 \mathrm{mM}$ sodium phosphate (pH 5.5) for $10 \mathrm{~min}$ at $37^{\circ} \mathrm{C}$. The reaction was terminated by adding $0.5 \mathrm{M}$ sodium carbonate and absorbance quantified at $405 \mathrm{~nm}$.

\section{Mice}

Five- to six-week-old female BALB/c mice were purchased from the Jackson Laboratory and used here. All mice were housed in specific-pathogen-free conditions according to the National Institutes of Health (NIH), and all animal experiments were conducted under protocols approved by the MGH Institutional Animal Care and Use Committee (IACUC), in compliance with appropriate ethical regulations. For all experiments, the allocation of age- and sex-matched mice to experimental groups was randomized, with four to five mice per group, each experiment being repeated three independent times. No statistical method was used to determine sample size.

PCA was conducted as described ${ }^{17}$. In brief, monoclonal ${ }^{\text {Sia }} \mathrm{mIgE}$ or ${ }^{\text {As }}$ mIgE specific for OVA or DNP (clone SPE-7, Sigma Aldrich) was injected intradermally into mouse ears. For experiments in which OVA-specific ${ }^{\mathrm{As}} \mathrm{mIgE}$ was added to OVA-specific ${ }^{\mathrm{Sia}} \mathrm{mIgE}$, an mIgE isotype control (clone MEA-36, Biolegend) was included. The next day, mice were intravenously challenged with $125 \mu \mathrm{g}$ OVA or DNP-HSA (both from Sigma Aldrich) and 2\% Evans blue dye in PBS. Forty-five minutes after challenge, the ears were excised and minced before incubation in $\mathrm{N}, \mathrm{N}$-dimethyl-formamide (EMD Millipore) at $55^{\circ} \mathrm{C}$ for $3 \mathrm{~h}$. The degree of blue dye in the ears was quantified by absorbance at $595 \mathrm{~nm}$.

PSA was elicited as described, with minor modifications ${ }^{31,32}$. In brief, mice were injected intravenously with monoclonal mIgE specific for OVA or DNP (clone SPE-7, Sigma Aldrich) in PBS, and challenged the next day intravenously with PBS containing $1 \mathrm{mg}$ OVA or DNP-HSA (both from Sigma Aldrich). To examine the therapeutic potential of ${ }^{\mathrm{As}} \mathrm{mIgE}$, on the first day we injected mice intravenously with $10 \mu \mathrm{g}$ DNP-specific mIgE (clone SPE-7, Sigma Aldrich); on the second day we injected them intravenously with PBS, $20 \mu \mathrm{g}$ OVA-specific ${ }^{\text {Sia }} \mathrm{mIgE}$ or $20 \mu \mathrm{g}$ OVA-specific ${ }^{\mathrm{As}} \mathrm{mIgE}$; and on the third day we challenged them intravenously with $1 \mathrm{mg}$ DNP-HSA or OVA (Sigma Aldrich). To test the therapeutic potential of $\mathrm{NEU}^{\mathrm{Fc \varepsilon}}$, mice injected intravenously with $10 \mu \mathrm{g}$ OVA-specific mIgE on the first day were further injected intravenously with PBS, $100 \mu \mathrm{g} \mathrm{NEU}{ }^{\mathrm{Fc \varepsilon}}$ or $100 \mu \mathrm{g}$ mIgE isotype control (clone MEA-36, 
Biolegend) the next day and challenged intravenously with $1 \mathrm{mg}$ OVA (Sigma-Aldrich) the third day. Core temperature was recorded at the baseline and every 10 min after allergen challenge in a blinded manner with a rectal microprobe thermometer (Physitemp). Histamine in the blood was quantified using a histamine enzyme immunoassay kit (SPI-Bio) according to the manufacturer's protocol. In brief, histamine in the blood was derivatized and incubated with plate precoated with monoclonal anti-histamine antibodies and histamine-acetylcholinesterase tracer at $4{ }^{\circ} \mathrm{C}$ for $24 \mathrm{~h}$. The plate was washed and developed with Ellman's reagent and absorbance measured at $405 \mathrm{~nm}$.

Passive food anaphylaxis was elicited by adapting the PSA protocol described above. In brief, mice injected intravenously with $20 \mu \mathrm{g}$ monoclonal mIgE specific for TNP (clone MEA-36, Biolegend) in PBS on the first day were administered with $20 \mathrm{mg}$ TNP-OVA in PBS (Biosearch Technologies) by oral gavage the next day. Core temperature was recorded at the baseline and every $10 \mathrm{~min}$ after the challenge using a rectal microprobe thermometer (Physitemp) in a blinded manner.

To determine in vivo half-lives of ${ }^{\mathrm{Sia}} \mathrm{mIgE}$ or ${ }^{\mathrm{As}} \mathrm{mIgE}$, we injected mice intraperitoneally with $30 \mu \mathrm{g}$ DNP-specific ${ }^{\mathrm{Sia}} \mathrm{mIgE}$ or ${ }^{\mathrm{As}} \mathrm{mIgE}$, and collected blood at the indicated times after injection into a Microtainer blood-collection tube with clot activator/serum separator tube (SST) gel (BD Diagnostics). We quantified the level of mIgE by mIgE ELISA as above.

\section{Basophil activation tests}

Basophil activation was performed as described ${ }^{33}$. Buffy coats of human blood from healthy, de-identified, consenting donors were obtained from the MGH Blood Transfusion Service. Peripheral blood mononuclear cells (PBMCs) were separated from buffy coats by density gradient centrifugation using Ficoll Paque Plus (GE Healthcare), and resuspended in $0.5 \%$ BSA in RPMI 1640 medium (GE Healthcare). PBMCs were incubated for $2 \mathrm{~min}$ with ice-cold lactic acid buffer $(13.4 \mathrm{mM}$ lactate, $140 \mathrm{mM} \mathrm{NaCl}, 5 \mathrm{mM} \mathrm{KCl}, \mathrm{pH} 3.9)$ to remove endogenous human IgE on the cell surface before neutralization with $12 \%$ Tris ( $\mathrm{pH} 8$ ). Cells were then washed and incubated $1 \mathrm{~h}$ at $37^{\circ} \mathrm{C}$ with $1 \mu \mathrm{g}$ OVA-specific Sia hIgE or ${ }^{\text {As }}$ hIgE per $1 \times 10^{6}$ cells in basophil activation buffer $(0.5 \% \mathrm{BSA}, 2 \mathrm{mM}$ $\mathrm{CaCl}_{2}$ and $2 \mathrm{mM} \mathrm{MgCl}_{2}$ in RPMI 1640 medium). Sensitized cells were washed and resuspended in basophil activation buffer supplemented with $10 \mathrm{ng} \mathrm{ml}^{-1}$ human interleukin-3 (PeproTech) before activation with OVA for $30 \mathrm{~min}$. Activation was stopped by addition of ice-cold $0.2 \mathrm{M}$ EDTA in FACS buffer. Cells were washed and resuspended in FACS buffer before antibody staining (Extended Data Table 3) for activation markers $\left(\mathrm{LAMP}^{-3}\right.$ or $\mathrm{CD}^{+} 3^{+}$) on basophils $\left(\mathrm{CD} 123^{+} \mathrm{HLADR}^{-}\right)$.

\section{Culture and degranulation of human mast cells}

The human LAD2 mast-cell line was a gift from D. D. Metcalfe (National Institute of Allergy and Infectious Diseases (NIAID), NIH) and was maintained as described ${ }^{17,34}$. In brief, LAD2 cells were cultured in StemPro-34 SFM medium (Life Technologies) supplemented with $2 \mathrm{mM} \mathrm{L-glutamine,}$ $100 \mathrm{U} \mathrm{ml}^{-1}$ penicillin, $100 \mathrm{\mu g} \mathrm{ml}^{-1}$ streptomycin and $100 \mathrm{ng} \mathrm{ml}^{-1}$ recombinant human stem cell factor (PeproTech). The cells were hemi-depleted each week with fresh medium and maintained at $2 \times 10^{5}$ to $5 \times 10^{5}$ cells per millilitre at $37^{\circ} \mathrm{C}$ and $5 \% \mathrm{CO}_{2}$.

Primary human mast cells were generated as described ${ }^{35}$. In brief, we separated PBMCs from buffy coats as above, before isolating CD34 ${ }^{+}$ pluripotent haematopoietic cells using the EasySep human whole blood CD34-positive selection kit II (Stemcell Technologies). We cultured CD34 ${ }^{+}$cells in StemPro-34 SFM medium (Life Technologies) supplemented with $2 \mathrm{mML}$-glutamine, $100 \mathrm{U} \mathrm{ml}^{-1}$ penicillin, $100 \mathrm{\mu g} \mathrm{ml}^{-1}$ streptomycin, $50 \mathrm{ng} \mathrm{ml}^{-1}$ recombinant human stem cell factor (PeproTech) and $50 \mathrm{ng} \mathrm{ml}^{-1}$ human interleukin-6 (PeproTech), and with $10 \mathrm{ng} \mathrm{ml}^{-1}$ human interleukin-3 (PeproTech) in the first week. After the first week we matured the cells in similar culture medium but without human interleukin-3 for ten weeks. Cultured mast cells were confirmed by FACS staining of $\mathrm{CD}^{+} 5^{+}, \mathrm{KIT}^{+}$and $\mathrm{Fc}_{\mathrm{RI}}{ }^{+}$.
Degranulation assays were performed as described ${ }^{17}$. LAD2 or peripheral blood derived human mast cells were sensitized overnight with $1 \mu \mathrm{g} \mathrm{ml}^{-1}$ OVA-specific hIgE or $50 \mathrm{ng} \mathrm{ml}^{-1}$ peanut-allergic hIgE. The following day, the cells were pelleted by centrifugation, resuspended in HEPES buffer, plated in 96-well plates, and stimulated with allergen OVA or crude peanut extract at defined concentrations. Upon allergen challenge, mast cell degranulation was determined by the amount of substrate $p$-nitrophenyl $N$-acetyl- $\beta$-D-glucosamide digested by $\beta$-hexosaminidase release from mast cell granules at absorbance of $405 \mathrm{~nm}$. To assess the effect of sialic acid removal on IgE-bound mast cells, we treated IgE-sensitized LAD2 cells with NEU ${ }^{\mathrm{Fc} \varepsilon}$, heat-inactivated NEU ${ }^{\mathrm{Fc \varepsilon}}$ or mIgE isotype control (clone MEA-36, Biolegend) for $20 \mathrm{~min}$ before allergen challenge. To inactivate $\mathrm{NEU}^{\mathrm{Fc \varepsilon}}$, we heated the enzyme at $95^{\circ} \mathrm{C}$ for $10 \mathrm{~min}$. To determine whether addition of a surrogate asialylated glycoprotein could recapitulate the phenotype of sialic acid removal from IgE, LAD2 cells sensitized with

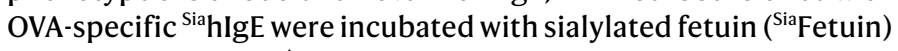
or asialylated fetuin ( ${ }^{\text {As }}$ Fetuin) at defined amounts for 20 min before allergen challenge.

\section{Preparation of crude peanut extract}

Unsalted dry-roasted peanuts (blanched jumbo runner cultivar, Planters) were ground to a smooth paste, then washed with 20 volumes of cold acetone, filtered using Whatman paper, and dried as described ${ }^{17}$. Protein was extracted by agitating the peanut flour overnight with PBS containing protease-inhibitor cocktail without EDTA (Roche). The peanut protein extracts were collected as the supernatant after centrifugation at $24,000 \mathrm{~g}$ for $30 \mathrm{~min}$.

\section{IgE glycosylation engineering}

To remove sialic acids on IgE, we digested IgE with glyko sialidase A (recombinant from $A$. urefaciens expressed in Escherichia coli, Prozyme) at $37^{\circ} \mathrm{C}$ for $72 \mathrm{~h}$ according to the manufacturer's instructions. To resialylate ${ }^{\mathrm{As}} \mathrm{mIgE}$ by in vitro sialylation, we incubated ${ }^{\mathrm{As}} \mathrm{mIgE}$ with human $\alpha-2,6$ sialyltransferase 1 (ST6GAL1, provided by H. Meade, LFB-USA) at a ratio of $20 \mu \mathrm{g}{ }^{\mathrm{As}} \mathrm{mIgE}$ per $\mu \mathrm{g}$ of ST6GAL1 and $5 \mathrm{mM}$ cytidine-5'-monophospho- $N$-acetylneuraminic acid (CMP-Neu5Ac2, Nacalai USA) in the sialylation buffer ( $150 \mathrm{mM} \mathrm{NaCl}, 20 \mathrm{mM}$ HEPES, $\mathrm{pH}$ 7.4) overnight at room temperature as described ${ }^{36}$. Following reactions, OVA-specific ${ }^{\mathrm{Sia}}$ IgE or ${ }^{\mathrm{As}}$ IgE was purified with OVA-coupled beads to remove glycosylation modifying enzymes as described ${ }^{17}$. All digestion or sialylation reactions were verified by lectin blotting or high-performance liquid chromatography (HPLC).

\section{Protein gel stain and lectin blotting}

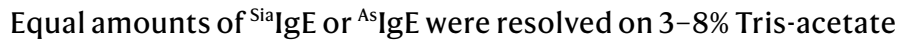
protein gels (Life Technologies) in SDS-PAGE under nonreducing conditions. For protein staining, gels were incubated in AcquaStain protein gel stain (Bulldog Bio) for $1 \mathrm{~h}$ at room temperature and destained in distilled water. For lectin blotting, the protocol was conducted as described ${ }^{17}$. Briefly, after resolved proteins on the gel were transferred to Immobilon-PSQ polyvinylidene difluoride membranes (Millipore Sigma), the membranes were blocked with $0.2 \%$ BSA in Tris-buffered saline (TBS) for $1 \mathrm{~h}$ at room temperature, washed in TBS, and then incubated with biotinylated S. nigra (SNA) lectin (0.4 $\mu \mathrm{g} \mathrm{ml}^{-1}$, Vector Laboratories) in TBS with $0.1 \mathrm{M} \mathrm{Ca}^{2+}$ and $0.1 \mathrm{M} \mathrm{Mg}^{2+}$ for $1 \mathrm{~h}$ at room temperature to determine the level of terminal $\alpha 2,6$-sialic acids on $\mathrm{N}$-linked glycans of proteins. The membrane was then washed in TBS and incubated with alkaline-phosphatase-conjugated goat anti-biotin (1:5,000 dilution; Vector Laboratories) in TBS for $1 \mathrm{~h}$ at room temperature. Sialylated proteins on membranes were visualized by incubation with one-step nitro-blue tetrazolium chloride (NBT)/5-bromo4-chloro-3'-indolyphosphate $p$-toluidine (BCIP) substrate solution (Thermo Scientific). 


\section{Flow cytometry}

Details of antibodies used for surface staining are listed in Extended Data Table 3. To stain mouse cells, we incubated suspended cells with anti-mouse CD16/CD32 (clone 2.4G2, BD Biosciences) before antibody staining. Cells were incubated in FACS buffer with desired staining antibodies for $20 \mathrm{~min}$ at $4{ }^{\circ} \mathrm{C}$. Cells were then washed in FACS buffer before being acquired by an LSRII flow cytometer (BD Biosciences) or CytoFLEX (Beckman Coulter). Data were analysed using FlowJo software version 10.4 software (Tree Star). To quantify OVA-specific hIgE loading following sensitization, we incubated PBS or $1 \mu \mathrm{g} \mathrm{ml}^{-1}$ OVA-specific ${ }^{\text {SiahIgE }}$ or ${ }^{\text {As }}$ hIgE with $2.5 \times 10^{5}$ LAD2 cells per millilitre overnight, before washing with FACS buffer and staining with anti-Kit antibody and OVA-A647. To quantify native hIgE loading on LAD2 mast cells, we sensitized cells with $32 \mathrm{ng}$ total non-atopic or allergic hIgE overnight before washing in FACS buffer and staining with anti-Kit and anti-hIgE antibodies. To quantify dermal mast cell IgE loading, we generated single-cell suspensions from mouse ears as described ${ }^{17}$. Ears were intradermally injected with 40 ng OVA-specific ${ }^{\text {Sia }} \mathrm{mIgE}$ or ${ }^{\text {As }}$ mIgE. The following day, ears were removed, separated into dorsal and ventral halves, and minced before incubation in Dulbecco's modified Eagle medium (DMEM) containing 2\% fetal calf serum (FCS), $1 \%$ HEPES, 500 units $\mathrm{ml}^{-1}$ collagenase type 4 (Worthington), $0.5 \mathrm{mg} \mathrm{ml}^{-1}$ hyaluronidase (Sigma) and DNase I (Roche) at $37^{\circ} \mathrm{C}$ for $1 \mathrm{~h}$ at $180 \mathrm{rpm}$. The digested sample was then subjected to disruption by gentleMACS and filtered through a $70-\mu \mathrm{m}$ cell strainer followed by a $40-\mu \mathrm{m}$ cell strainer in FACS buffer (2 mM EDTA and 0.5\% BSA in PBS). mIgE loading was detected by FACS using anti-mIgE antibodies on dermal mast cells

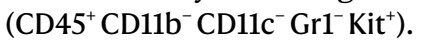

\section{Biolayer interferometric assays for binding}

We studied binding kinetics and affinity of protein interaction using the Octet K2 system (Molecular Devices) with Octet buffer (PBS with $0.025 \%$ Tween and $1 \% \mathrm{BSA}$ ). To measure hFceRI $\alpha$ interactions, $0.25 \mathrm{\mu g} \mathrm{ml}^{-1}$ histidine-tagged hFceRI $\alpha$ (Acro Biosystems) was loaded onto anti-penta-histidine (HIS1K) biosensors (Molecular Devices). To analyse OVA interactions, we immobilized OVA $\left(100 \mu \mathrm{g} \mathrm{ml}^{-1}\right)$ onto amine-reactive second-generation (AR2G) biosensors in $10 \mathrm{mM}$ sodium acetate, $\mathrm{pH} 5$, using 1-ethyl-3-(3-dimethylaminopropyl)carbodiimide hydrochloride (EDC)/sulfo-NHS based chemistry. We determined association of analyte OVA-specific ${ }^{\text {Siah }}$ IgE or ${ }^{\text {As }}$ hIgE in threefold serial dilution from $90 \mathrm{nM}$ to $1 \mathrm{nM}$, and of $\mathrm{NEU}^{\mathrm{FC}}$ in threefold serial dilution from $24 \mathrm{nM}$ to $0.3 \mathrm{nM}$ in Octet buffer. Analyte dissociation was measured in Octet buffer. Analysis of binding kinetic parameters was performed by Octet data analysis software v.10.0, using interaction of ligand-loaded biosensor with no analyte during the association phase as the reference sensor.

\section{Immunoblotting for Syk signalling}

We sensitized $1.5 \times 10^{6} \mathrm{LAD} 2$ cells with PBS or $1 \mu \mathrm{g} \mathrm{ml}^{-1} \mathrm{OVA}$-specific

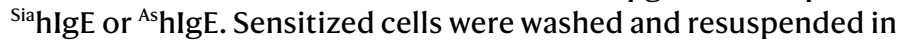
HEPES buffer the next day, and then stimulated with $10 \mu \mathrm{g} \mathrm{ml}^{-1} \mathrm{OVA}$ at $37^{\circ} \mathrm{C}$ for the indicated times. Cells were immediately centrifuged after OVA stimulation and the cell pellets lysed in ice-cold lysis buffer (RIPA buffer (Boston BioProducts), $1 \times$ Halt protease-inhibitor cocktail (Thermo Scientific), $1 \times$ Halt phosphatase-inhibitor cocktail (Thermo Scientific) and 2.5 mM EDTA) for 30 min on ice. After incubation on ice, lysed pellets were passed rapidly through a $27 \mathrm{G}$ needle on ice and centrifuged at $15,000 \mathrm{rpm}$ at $4{ }^{\circ} \mathrm{C}$ for $15 \mathrm{~min}$ to clear the membrane and nuclei. The protein concentration was quantified using a Pierce BCA protein assay kit (Thermo Scientific) and $20 \mu \mathrm{g}$ of protein lysate was loaded per well on 4-12\% Bis-Tris protein gels (Life Technologies) in SDS-PAGE under denaturing and reducing conditions. Briefly, after protein transferred to PVDF membranes as above, the membranes were blocked with 5\% milk in TBS with $0.1 \%$ Tween (TBST) for $1 \mathrm{~h}$ at room temperature, washed in TBST, and incubated with 1:2,000 rabbit
anti-phospho-Syk (Tyr352) antibody (Cell Signaling Technology) in $5 \%$ BSA in TBST overnight at $4{ }^{\circ} \mathrm{C}$. The membrane was washed in TBST, incubated with anti-rabbit-HRP for $1 \mathrm{~h}$ at room temperature, and washed again in TBST; this was followed by chemiluminescent detection using Immobilon western chemiluminescent HRP substrate (Millipore Sigma). To detect total Syk on the membrane, after chemiluminescent detection using autoradiography film, the membrane was stripped by incubation in stripping buffer $(2 \%$ SDS and $0.1 \mathrm{M} \beta$-mercaptoethanol in Tris buffer) at $50^{\circ} \mathrm{C}$ for $30 \mathrm{~min}$. The stripped membranes were then blocked, washed as above, incubated with 1:2,000 rabbit anti-Syk antibody (Cell Signaling Technology) for $2 \mathrm{~h}$ in 5\% BSA in TBST at room temperature, and washed again before being incubated with 1:30,000 anti-rabbit-HRP for $1 \mathrm{~h}$ at room temperature. To probe for $\beta$-actin, the membranes were incubated with 1:150,000 anti- $\beta$-actin HRP (Santa Cruz Biotechnology) for $1 \mathrm{~h}$ at room temperature and then washed; signal was determined by chemiluminescent detection.

\section{Calcium flux}

We sensitized $5 \times 10^{5}$ LAD2 cells overnight with PBS or $500 \mathrm{ng} \mathrm{ml}^{-1}$ OVA-specific ${ }^{\text {SiahlgE }}$ or ${ }^{\text {As }}$ hIgE. The next day, sensitized cells were washed before loading with $2 \mu \mathrm{M}$ Fluo-4-AM (Invitrogen) at $37^{\circ} \mathrm{C}$ in HEPES buffer for $20 \mathrm{~min}$. After loading, the cells were washed and resuspended in HEPES buffer. Fluorescence was filtered through the 530/30 bandpass filter and collected in FL-1/FITC. Baseline $\mathrm{Ca}^{2+}$ fluorescence levels were recorded for $1 \mathrm{~min}$ on the Accuri C6 (BD Biosciences) before adding the indicated allergen or buffer to each sample. At the end of allergen stimulation, $2 \mu \mathrm{M} \mathrm{Ca}^{2+}$ ionophore A23187 (Sigma) was added to cells as a positive control.

\section{Statistical analyses}

Results are shown as means \pm s.e.m., except in the case of gMS-quantified glycan residues per IgE molecule (Fig. $1 d-h)$, where results are presented as medians and interquartile ranges. The number of mice used in each experiment is indicated in the figure legends. The investigators were not blinded to allocation during experiments and outcome assessment, except during the measurement of rectal temperature in mice upon antigen challenge in passive systemic and food anaphylaxis. Visual examination of the data distribution as well as normality testing demonstrated that all variables appeared to be normally distributed. Statistical analyses were performed using Prism 8 (GraphPad software) with unpaired and paired Student's $t$-test for assessing two unmatched and matched groups, respectively; two-way ANOVA with Sidak's multiple comparison test for comparing two groups of multiple conditions; and one-way or two-way ANOVA with Tukey's multiple comparison test for three or more groups. The $P$ values noted throughout highlight biologically relevant comparisons. The accuracy of distinguishing allergic from non-atopic IgE by means of individual IgE glycan moieties was analysed by ROC curves using Prism 8 (GraphPad software). The area under each ROC curve (AUC) was calculated for each glycan moiety. AUCs are interpreted as follows: the maximum AUC (1) indicates that a particular glycan moiety can distinguish allergic IgE from non-atopic IgE; an AUC of 0.5 indicates that the differentiation capacity of a specific glycan moiety is poor.

\section{Reporting summary}

Further information on research design is available in the Nature Research Reporting Summary linked to this paper.

\section{Data availability}

Source Data are provided for Figs. 1-3 and Extended Data Figs. 1, 4-7. Full scans of all uncropped protein gel stains, lectin blots and western blots with size marker indications presented here can be found in the Supplementary Information. All other data supporting the findings of this study are available from the corresponding author upon request. 


\section{Article}

30. Christensen, S. \& Egebjerg, J. Cloning, expression and characterization of a sialidase gene from Arthrobacter ureafaciens. Biotechnol. Appl. Biochem. 41, 225-231 (2005).

31. Dombrowicz, D. et al. Anaphylaxis mediated through a humanized high affinity lgE receptor. J. Immunol. 157, 1645-1651 (1996).

32. Dombrowicz, D., Flamand, V., Brigman, K. K., Koller, B. H. \& Kinet, J. P. Abolition of anaphylaxis by targeted disruption of the high affinity immunoglobulin $E$ receptor alpha chain gene. Cell 75, 969-976 (1993).

33. MacGlashan, D. Jr, Lavens-Phillips, S. \& Katsushi, M. IgE-mediated desensitization in human basophils and mast cells. Front. Biosci. 3, d746-d756 (1998).

34. Kirshenbaum, A. S. et al. Characterization of novel stem cell factor responsive human mast cell lines LAD 1 and 2 established from a patient with mast cell sarcoma/leukemia; activation following aggregation of FceRI or FcyRI. Leuk. Res. 27, 677-682 (2003).

35. Bandara, G., Metcalfe, D. D. \& Kirshenbaum, A. S. Growth of human mast cells from bone marrow and peripheral blood-derived CD34 ${ }^{+}$pluripotent hematopoietic cells. Methods Mol. Biol. 1220, 155-162 (2015).

36. Anthony, R. M. et al. Recapitulation of IVIG anti-inflammatory activity with a recombinant IgG Fc. Science 320, 373-376 (2008)

Acknowledgements We thank K. Jeffrey, F. Wermeling and A. Luster for constructive comments; T. Stanley and D. Hayden (Harvard Catalyst) for guidance in biostatistical analysis; N. Smith for technical assistance; and the patients participating in our studies. This work was supported by grants from the NIH (DP2AR068272 and R01Al139669) and FARE to R.M.A.; NIH T32 and K12 fellowships (T32AR007258 and K12HL141953) to K.C.S.; an NIH NIAID K23 grant (K23Al121491) to S.U.P.; an NIH NIAID U19 grant (5U19 AI095261-03) to W.G.S.; and a Sanofi iAward to M.E.C.

Author contributions K.C.S. conducted mouse experiments, performed functional assays, developed methods, and generated resources, along with D.J.H.; M.K. cloned, generated and characterized NEU ${ }^{\mathrm{Fc}}$; M.E.C. purified samples and analysed data, along with E.L.; N.W. performed mass spectrometry on purified samples; S.U.P. and W.G.S. acquired patient sample resources; S.U.P. and W.G.S. provided collected clinical samples; and R.M.A. conceived and supervised the study, and wrote the manuscript along with K.C.S., M.E.C., S.U.P. and W.G.S.

Competing interests The authors declare no competing interests

Additional information

Supplementary information is available for this paper at https://doi.org/10.1038/s41586-020 2311-z.

Correspondence and requests for materials should be addressed to R.M.A.

Peer review information Nature thanks Steve Galli, Kari Nadeau and Jim Paulson for their contribution to the peer review of this work.

Reprints and permissions information is available at http://www.nature.com/reprints. 

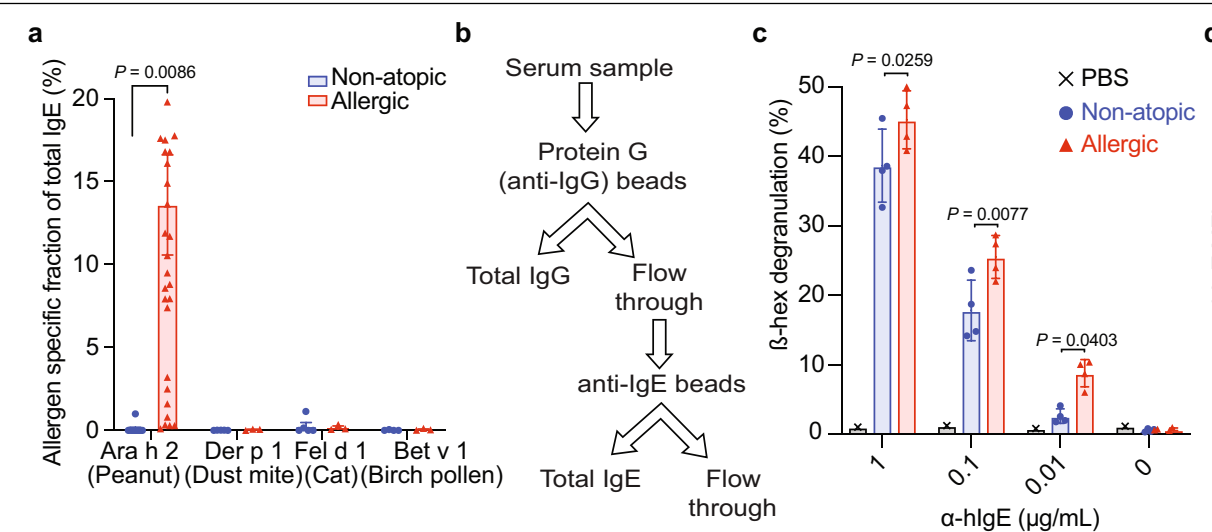

\section{d}

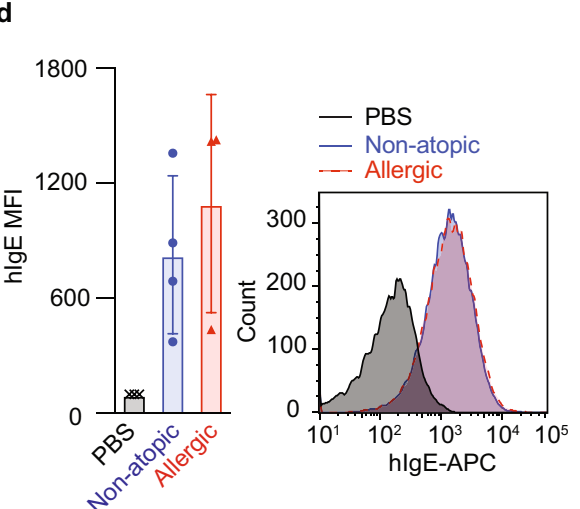

e

f

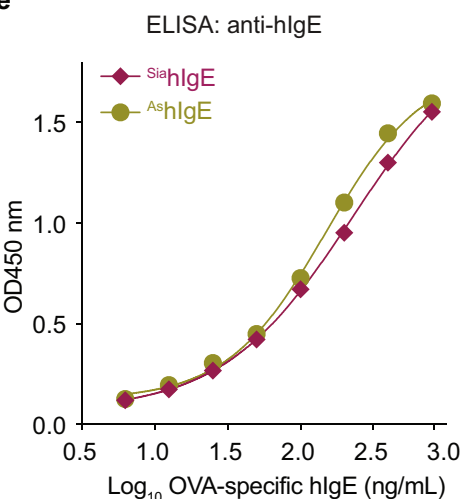

$\diamond$ Female $\times$ Male

g IgE by age $\bullet-0-9 \quad$ - 20-29 $\vee 40-49 \cdot 60-69$

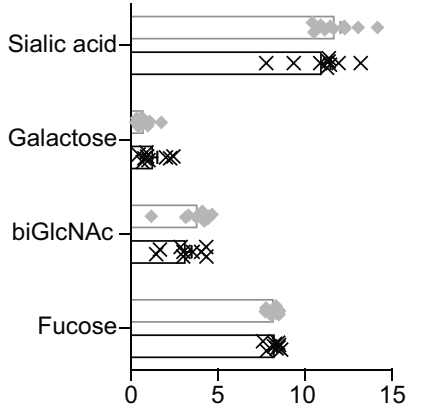

Total \# glycan residues per lgE molecule

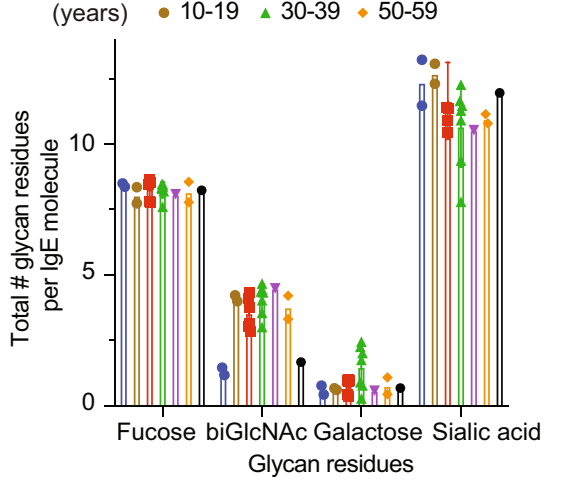

h

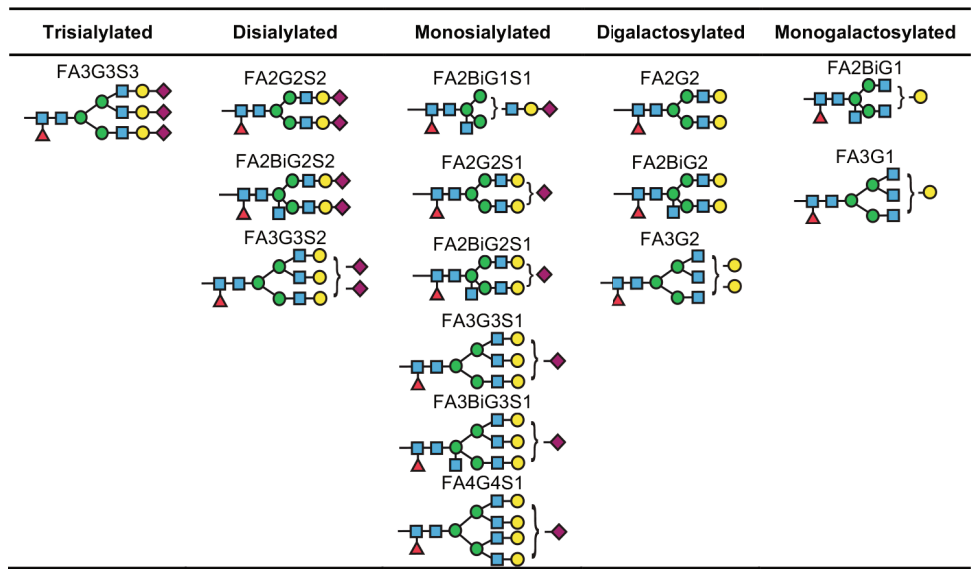

Extended Data Fig. 1 | Characterization of non-atopic and allergic human

IgE. a, Allergen-specific IgE levels for Ara h 2 (peanut; non-atopic, $n=11$; allergic, $n=30$ ), Der 1 (dust mite; $n=5,3$ ), Fel d 1 (cat; $n=5,3$ ) and Bet 1 (birch pollen; $n=4,3)$. b. Strategy for enriching IgE from human sera. c, Quantified degranulation of human LAD2 mast cells sensitized with PBS, non-atopic IgE or allergic IgE and stimulated with anti ( $\alpha$ )-human IgE (PBS, $n=1$; non-atopic, $n=4$; allergic, $n=4$ ).d, Quantified MFI (left) and representative histograms (right) of anti-hIgE FACS staining on human LAD2 mast cells sensitized with PBS, non-atopic hIgE or allergic hIgE (PBS, $n=3$; non-atopic, $n=4$; allergic, $n=3$ ).
APC, allophycocyanin. e, Anti-hIgE from c, d binds similarly to ${ }^{\text {Sia }}$ hIgE and ${ }^{\text {As }}$ hIgE, as determined by hIgE ELISA assays. $n=2$ technical replicates per group, representative of three experiments. $\mathbf{f}, \mathbf{g}$, IgE glycan distribution by $\operatorname{sex}(\mathbf{f} ; n=9$ males; $n=12$ females) and age (g; $0-9$ years, $n=2 ; 10-19, n=2 ; 20-29, n=6 ; 30$ $39, n=7 ; 40-49, n=1 ; 50-59, n=2 ; 60-69, n=1) . \mathbf{h}$, Representative structures of complex $\mathrm{N}$-linked glycans from Fig. 1j. Data shown are means \pm s.e.m.

$(\mathbf{a}, \mathbf{c}, \mathbf{d}, \mathbf{f}, \mathbf{g}) . P$-values were determined by two-tailed unpaired $t$-test $(\mathbf{d}, \mathbf{f})$ or two-way ANOVA with Sidak's multiple comparison test $(\mathbf{a}, \mathbf{c}, \mathbf{g}) . n$ represents biologically independent serum samples $(\mathbf{a}, \mathbf{c}, \mathbf{d}, \mathbf{f}, \mathbf{g})$. 


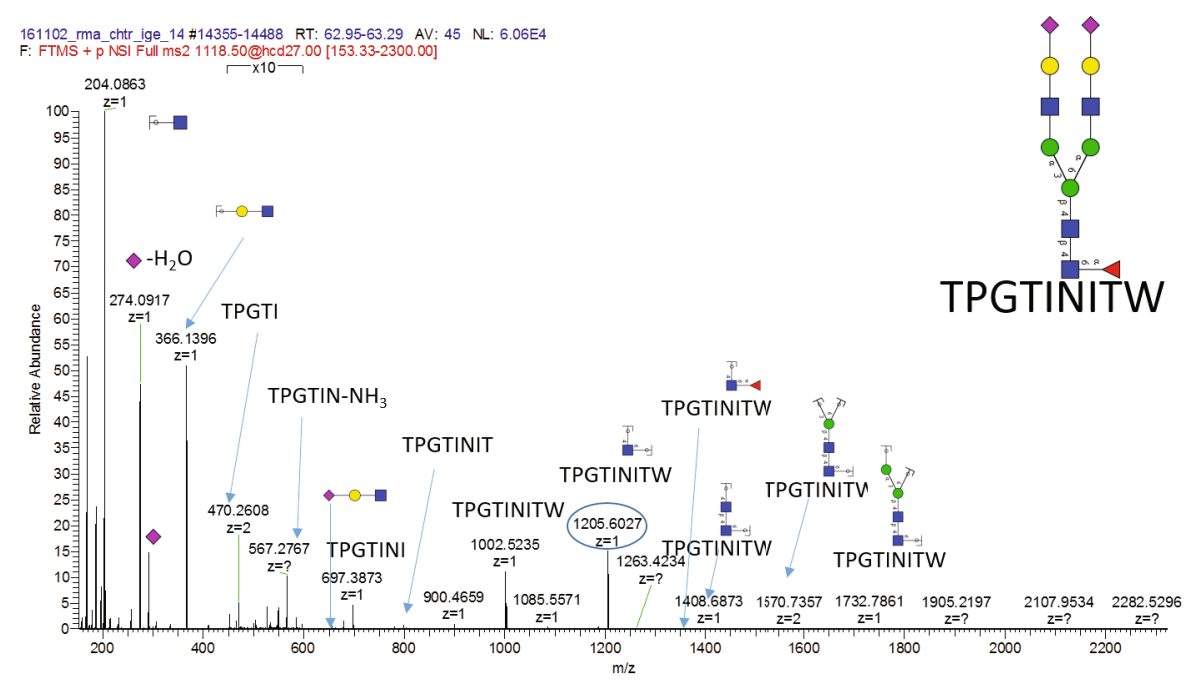

b

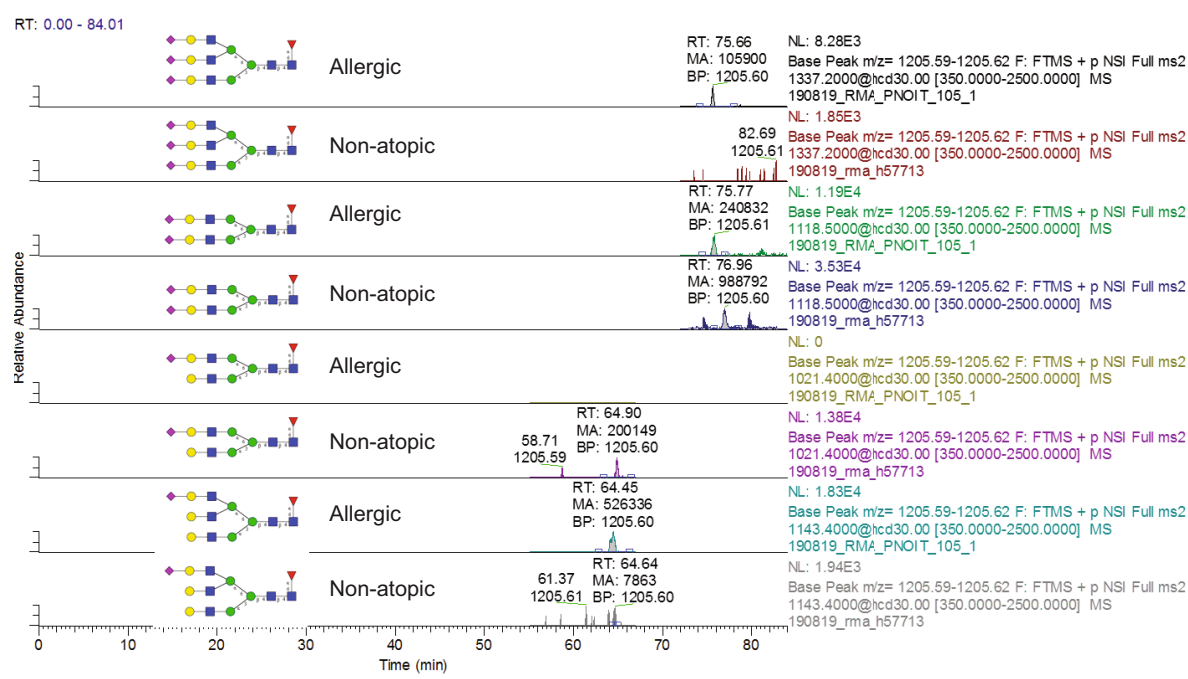

c

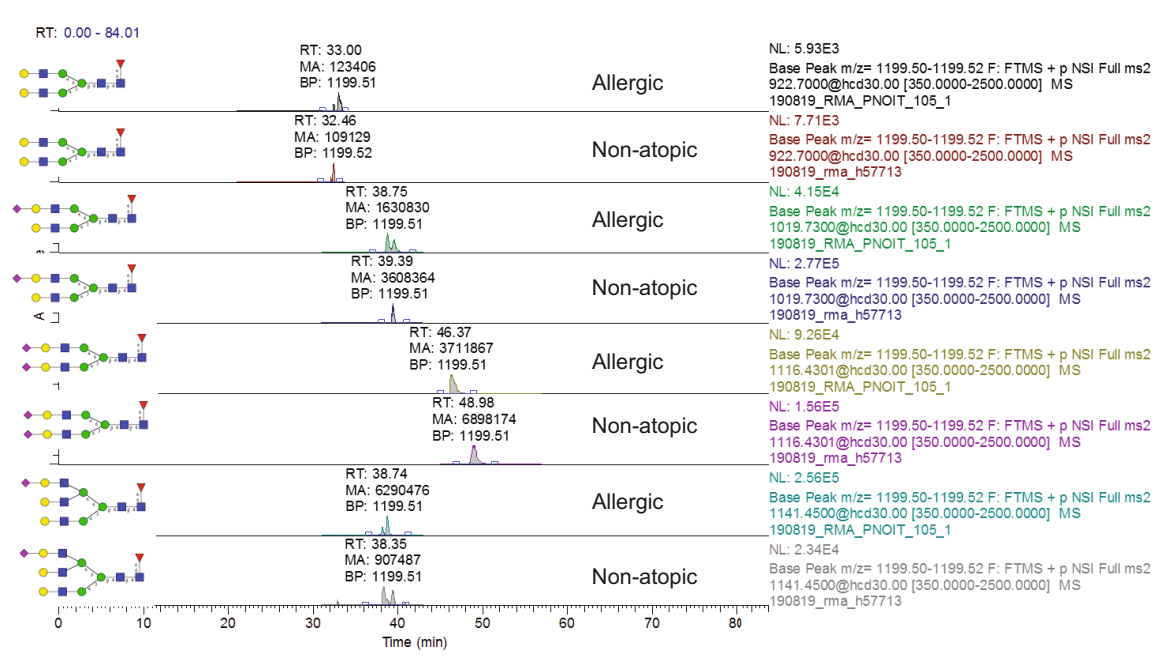

Extended Data Fig. 2 | $\mathbf{N}$-linked glycans observed on native human IgE. a, Representative MS/MS spectrum for N265-linked A2F glycopeptide, showing the $B$ ions (non-reducing end fragments) and $\mathrm{Y}$ ions (reducing end fragments containing the intact peptide) resulting from glycosidic-bond cleavage, and the $b$ ions containing the peptide $\mathrm{N}$ terminus resulting from peptide-bond cleavage. The Y1 ion used for quantification of glycopeptides is circled $(n=18$ biologically independent samples).b, Extracted ion chromatograms for IgE N265-linked sialylation variants from a patient with an allergy and a non-atopic donor.c, Extracted ion chromatograms for IgE N168-linked sialylation variants from a patient with an allergy and a non-atopic donor. $\mathrm{AV}$, average (referring to the number of spectra averaged); $\mathrm{BP}$, base peak; MA, manual integration; RT, retention time. 
a

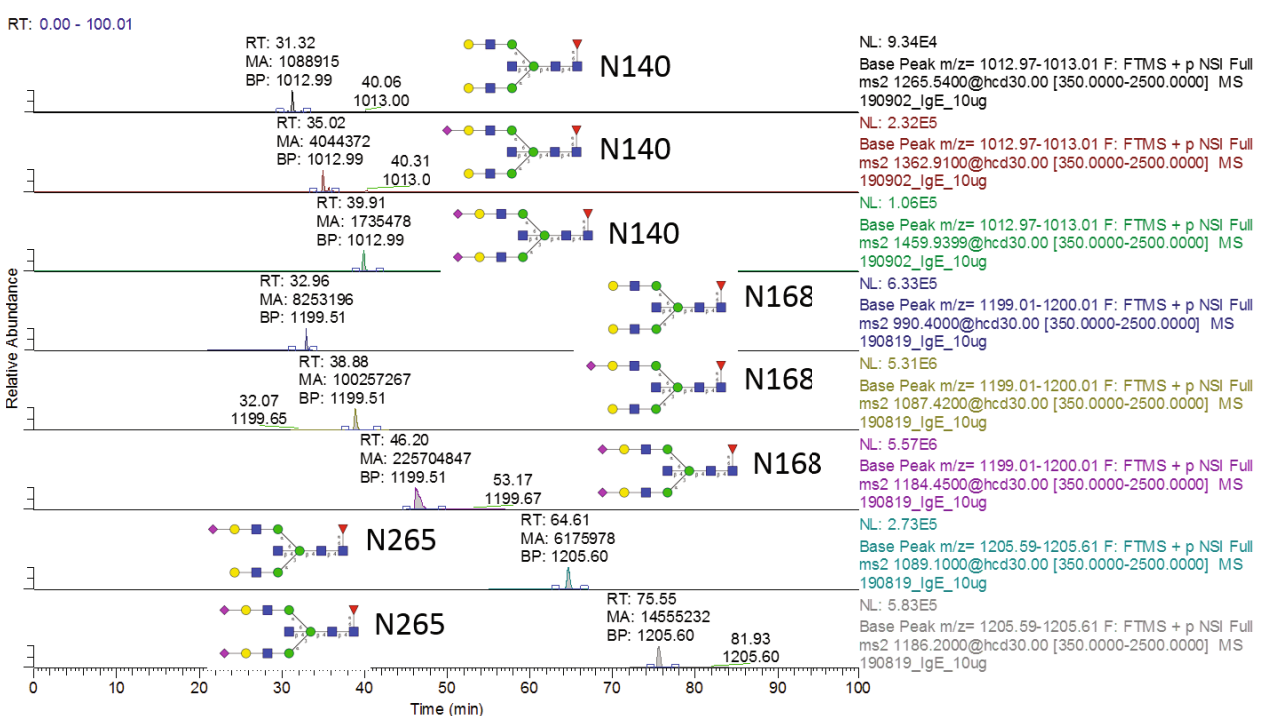

b

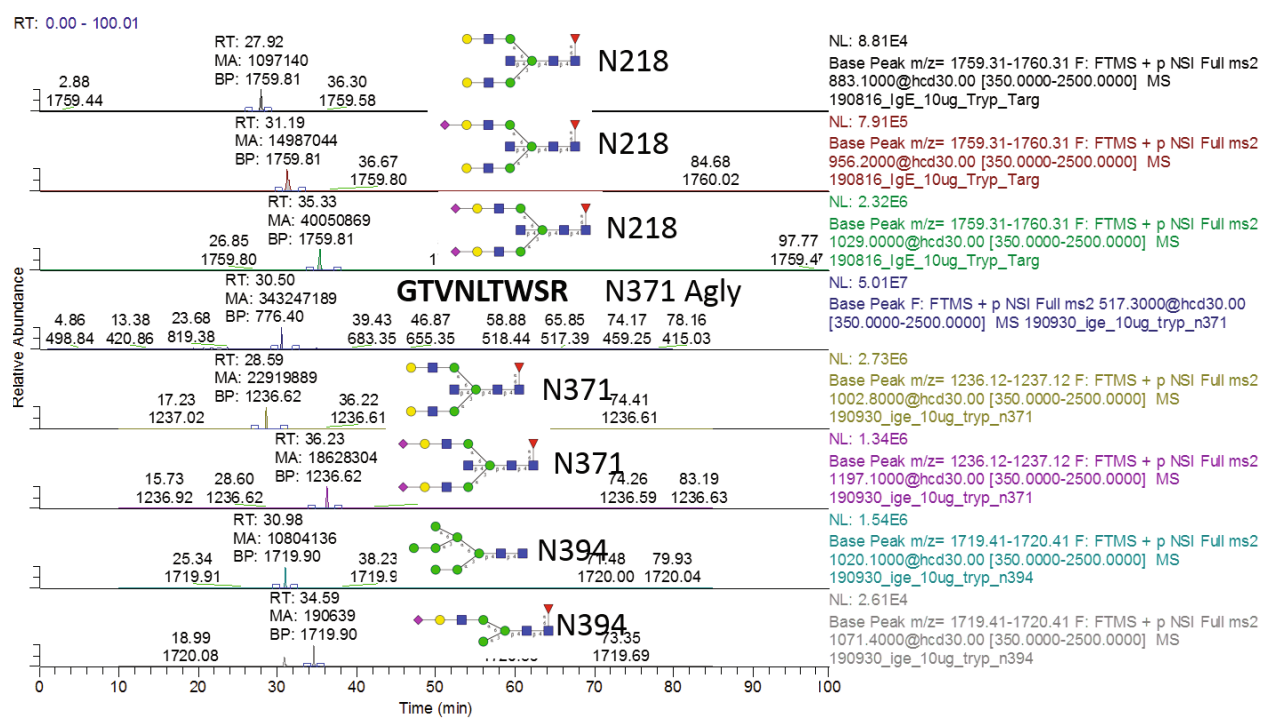

Extended Data Fig. 3 | N-linked glycans observed on IgE myeloma standard. a, b, Extracted ion chromatograms for site-specific $\mathrm{N}$-linked glycosylation from chymotryptic (a) or tryptic (b) digest of the IgE myeloma sample used as a standard. 
a

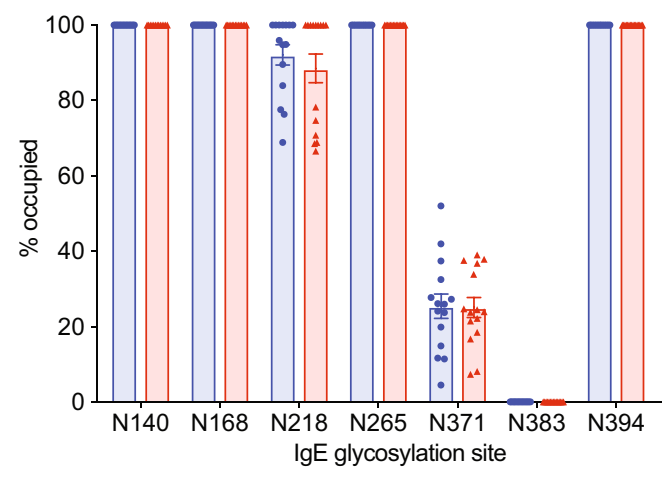

c

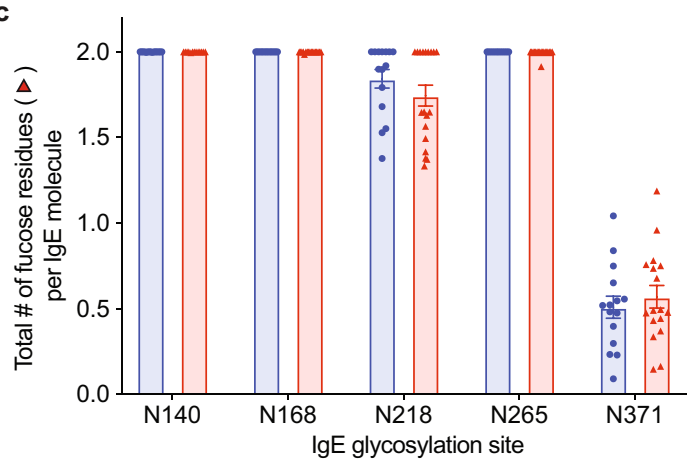

e

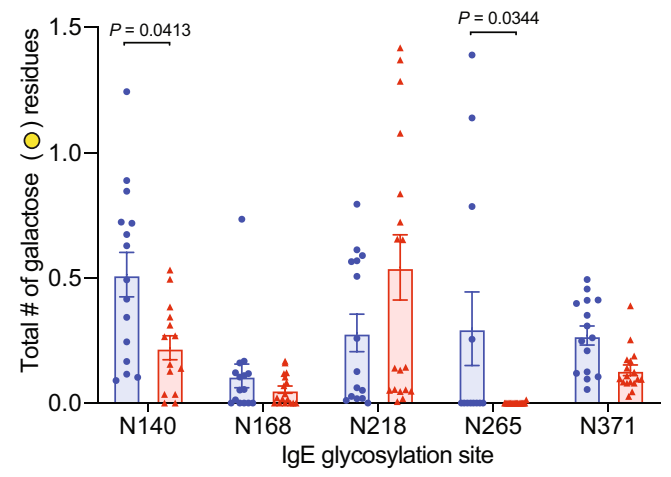

Extended Data Fig. 4 | Site-specific characterization of resolved IgE glycans from non-atopic individuals and individuals with allergies. a, Occupancy of $\mathrm{N}$-linked glycosylation sites: N140 (non-atopic, $n=15$; allergic, $n=13$ ), N168 $(n=16,14), \mathrm{N} 218(n=15,15), \mathrm{N} 265(n=12,15), \mathrm{N} 371(n=15,15), \mathrm{N} 383(n=16,15)$ and N394 $(n=13,16)$. b. Percentage of oligomannose moieties at $\mathrm{N} 394(n=23$, 18). c, Number of fucose residues: $\mathrm{N} 140(n=15,13), \mathrm{N} 168(n=15,17), \mathrm{N} 218(n=15$, 19), $\mathrm{N} 265(n=12,18)$ and N371 $(n=15,17)$. d, Number of biGlcNAc residues: $\mathrm{N} 140$ b

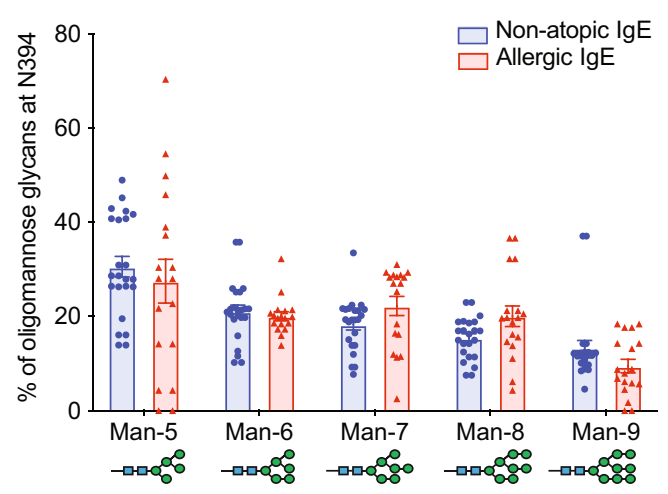

d

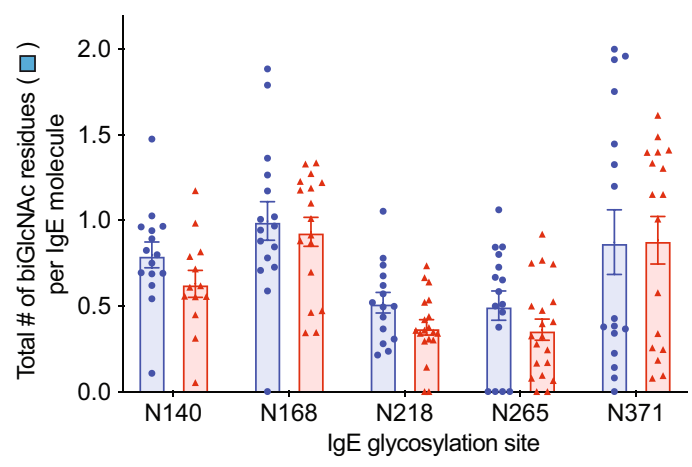

f

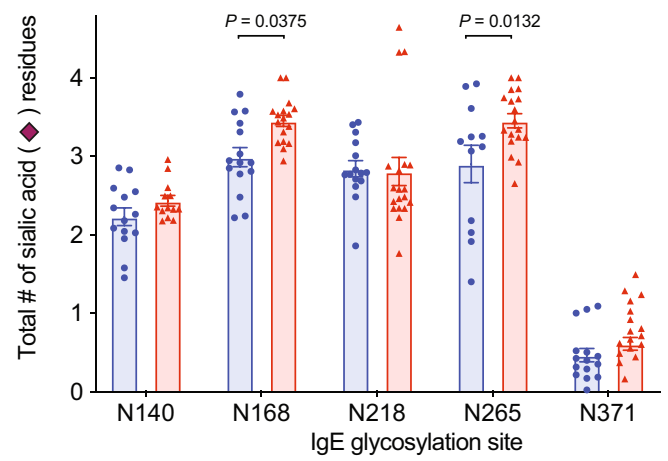

$(n=15,13), \mathrm{N} 168(n=16,17), \mathrm{N} 218(n=15,19), \mathrm{N} 265(n=16,20)$ and $\mathrm{N} 371(n=16$ 17).e, Number of galactose residues: $\mathrm{N} 140(n=15,14), \mathrm{N} 168(n=15,17), \mathrm{N} 218$ $(n=15,19), \mathrm{N} 265(n=12,19)$ and $\mathrm{N} 371(n=15,17) . \mathbf{f}$, Number of sialic acid residues: $\mathrm{N} 140(n=14,13), \mathrm{N} 168(n=15,13), \mathrm{N} 218(n=15,17), \mathrm{N} 265(n=12,19)$ and $\mathrm{N} 371(n=15,17)$. Data plotted are means \pm s.e.m. $P$ values were determined by two-way ANOVA with Sidak's multiple comparison test. $n$ represents biologically independent serum samples $(\mathbf{a}-\mathbf{f})$. 
a

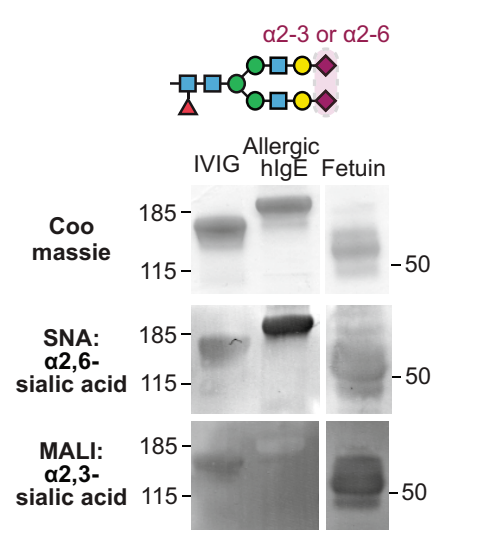

d

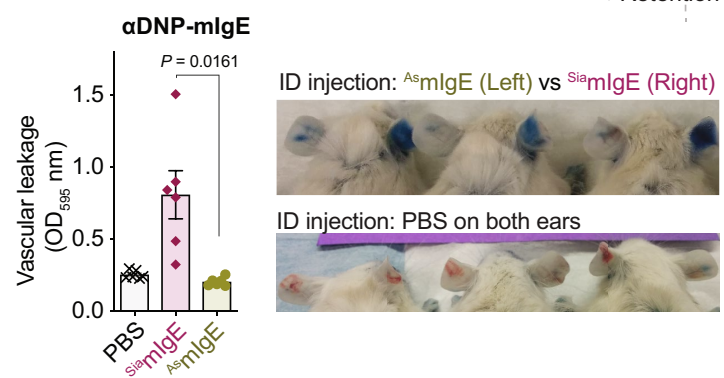

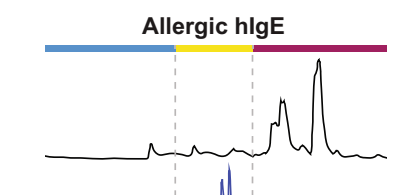

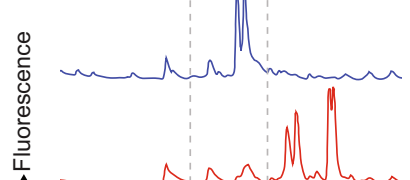

$\rightarrow$ Retention Time (min)

c

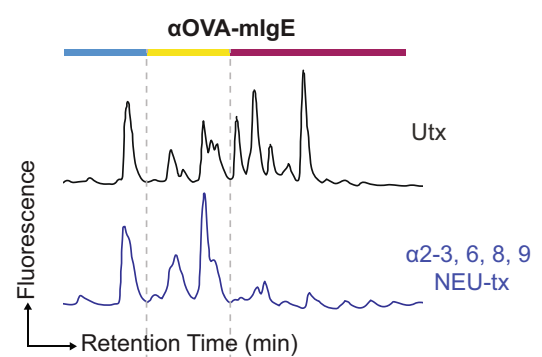

Fetuin

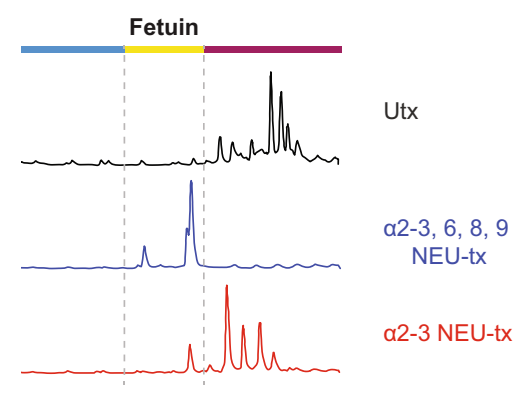

Agalactosylated

Galactosylated

- Sialylated

e Live cells

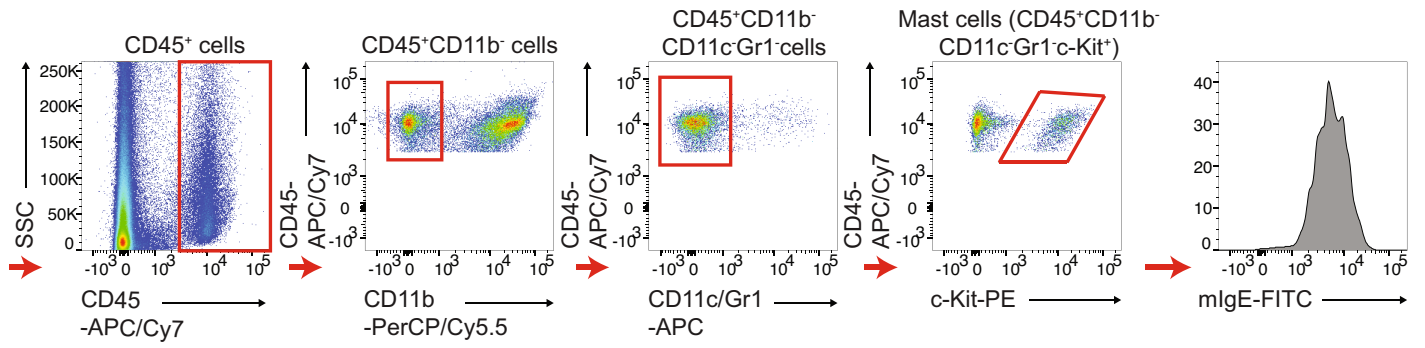

f

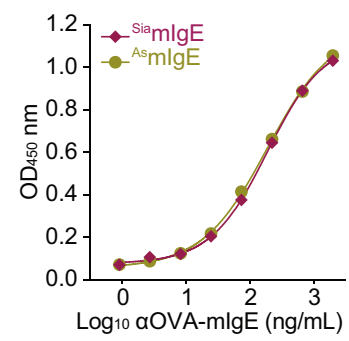

g

\begin{tabular}{|c|c|}
\hline $\begin{array}{l}\text { D0: i.v. } \\
\downarrow \text { sensitization }\end{array}$ & $\begin{array}{l}\text { D1: i.v. } \\
\quad \text { challenge }\end{array}$ \\
\hline $\begin{array}{l}\text { SiamlgE or }{ }^{A s} \mathrm{mlgE} \\
\text { or PBS }\end{array}$ & $\mathrm{OV}$ \\
\hline
\end{tabular}

* PBS

$\because$ OVA-specific AsmlgE

$\rightarrow$ OVA-specific siamlgE

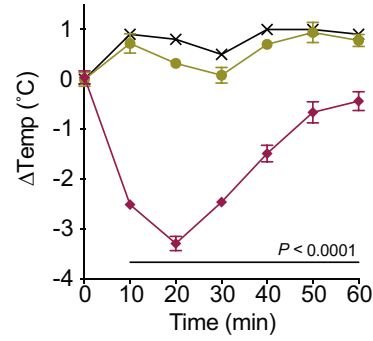

h

\begin{tabular}{|ll|}
\hline D0: i.p. & D1: i.v. \\
$\downarrow$ sensitization & $\downarrow$ challenge \\
\hline $\begin{array}{l}\text { SiamlgE or }{ }^{\text {As }} \text { mlgE } \\
\text { or PBS }\end{array}$ & OVA \\
\hline
\end{tabular}

* PBS

* OVA-specific AsmlgE

$\rightarrow$ OVA-specific siamlgE

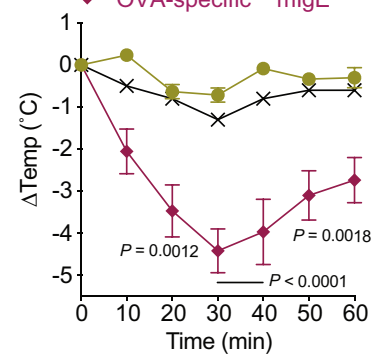

i

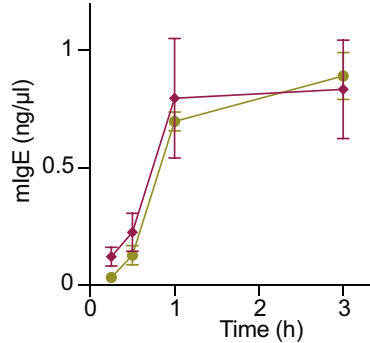

Extended Data Fig. 5 | See next page for caption. 


\section{Article}

Extended Data Fig. $5 \mid$ Removal of sialic acid from IgE. a, Protein gel stain and lectin blots of IVIG, native human IgE purified from patients with allergies, and fetuin. MALI,Maackia amurensis lectin I. b, HPLC glycan traces of undigested (Utx) allergic hIgE and fetuin; of allergic hIgE and fetuin digested with sialidase from $A$. ureafaciens to release $\alpha 2,3-, \alpha 2,6-, \alpha 2,8$ - and $\alpha 2,9$-linked sialic acids $(\alpha 2-3,6,8,9$ NEU-tx); and allergic hIgE and fetuin digested with sialidase from Streptococcus pneumoniae to release $\alpha 2,3$-linked sialic acids ( $\alpha 2-3 \mathrm{NEU}-\mathrm{tx}$ ). c, HPLC glycan traces of undigested or recombinant OVA-specific mIgE digested with sialidase from $A$. ureafaciens. d, Left, quantification of vascular leakage by Evan's blue dye ( $n=6$ mouse ears per group) after PCA in mice sensitized with PBS or with ${ }^{\text {Sia }} \mathrm{mIgE}$ or ${ }^{\mathrm{As}} \mathrm{mIgE}$ specific for DNP; right, representative ear images. e, Gating strategy for IgE loading on mouse skin ear mast cells. Shown are representative FACS plots used to identify mast cells in mouse ears and to determine IgE levels on mouse ear mast cells. SSC, side scatter.f, Binding of OVA-specific ${ }^{\mathrm{Sia}} \mathrm{mIgE}$ and ${ }^{\mathrm{As}} \mathrm{mIgE}$ to OVA, as determined by ELISA. $n=2$ technical replicates per group, representative of three biologically independent experiments. $\mathbf{g}, \mathbf{h}$, OVA-elicited systemic anaphylaxis as measured by temperature drop in mice sensitized with PBS, OVA-specific ${ }^{\text {Sia }} \operatorname{mIgE}(\mathbf{g}, n=4 ; \mathbf{h}, n=6)$ or OVA-specific ${ }^{\mathrm{As}} \operatorname{mIgE}(\mathbf{g}, n=5 ; \mathbf{h}, n=6)$ by intravenous (g) or intraperitoneal (h) injection. $\mathbf{i}$, Serum levels of DNP-specific ${ }^{\text {Sia }} \mathrm{mIgE}$ $(n=4)$ and ${ }^{\mathrm{As}} \mathrm{mIgE}(n=3)$ in mice at defined times after systemic administration, determined by ELISA. Data are means \pm s.e.m. and are representative of three experiments. $P$ values determined by two-tailed paired $t$-test $(\mathbf{d})$ or two-way ANOVA with Tukey's multiple comparison test $(\mathbf{g}, \mathbf{h})$. 
a

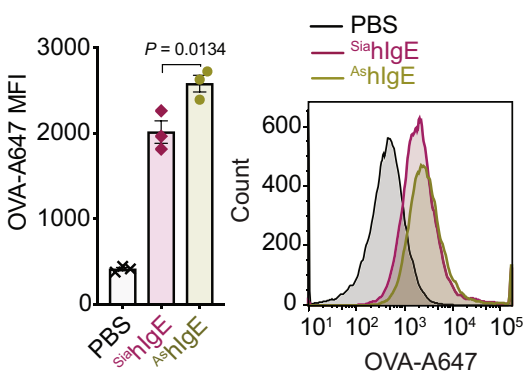

b

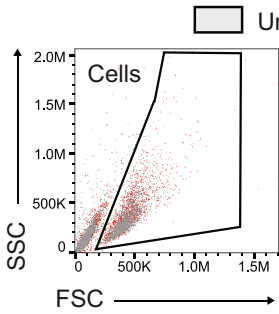

Unstained control

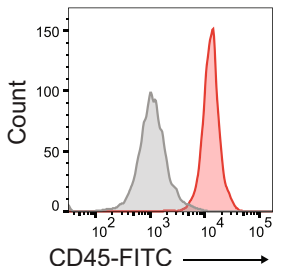

Stained with indicated antibodies
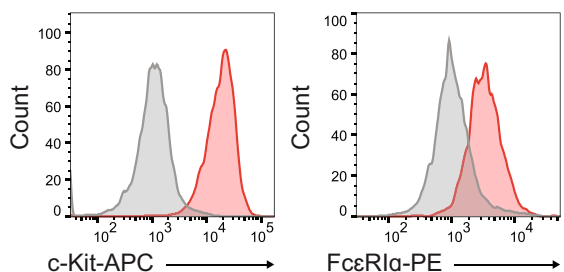

c
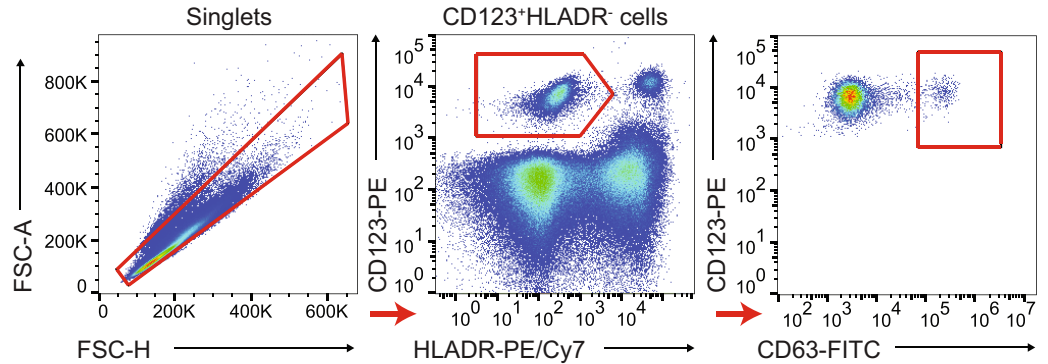

Extended Data Fig. 6 | FACS analysis of loading of human mast cells with

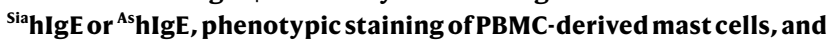
activation in primary basophils. a, MFI (left) and representative histogram (right) of surface-bound hIgE on LAD2 mast cells following sensitization with

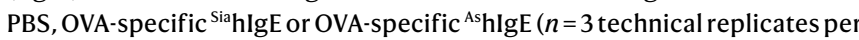
group). Data are means \pm s.e.m. and are representative of three independent experiments; one-way ANOVA with Tukey's multiple comparison test. b, Representative phenotypic staining by FACS of primary human mast cells from peripheral blood derived CD34 ${ }^{+}$pluripotent haematopoietic cells $(n=2$ technical replicates per group).c, Gating strategy for basophil activation assay, showing representative FACS plots used to determine basophil activation from PBMCs. 


\section{Article}

\begin{tabular}{|c|c|c|c|}
\hline D0: i.v. & D1: i.v. & \multirow{2}{*}{\multicolumn{2}{|c|}{ D2: i.v. challenge }} \\
\hline$\downarrow$ sensitization & treatment & & \\
\hline $\begin{array}{l}* \text { *aDNP_siamlg } \\
\diamond \text { aDNP_siamlg } \\
\ominus \text { aDNP_siamlg }\end{array}$ & $\begin{array}{l}\text { +PBS } \\
\text { + }+ \text { OVA_SiamlgE }(20 \mu \mathrm{g}) \\
+\alpha O V A-A s m l g E(20 \mu \mathrm{g})\end{array}$ & OVA & $\begin{array}{l}\text { Measure } \\
\text { Temp }\end{array}$ \\
\hline
\end{tabular}

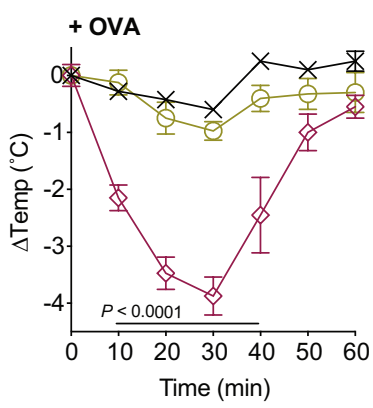

b
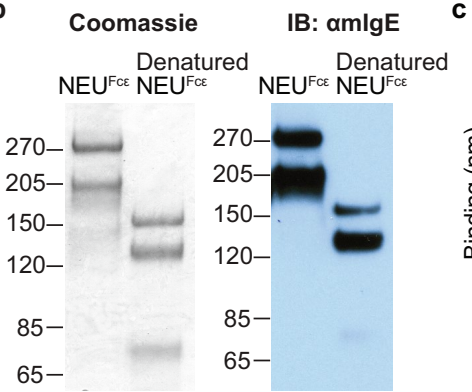

(6)
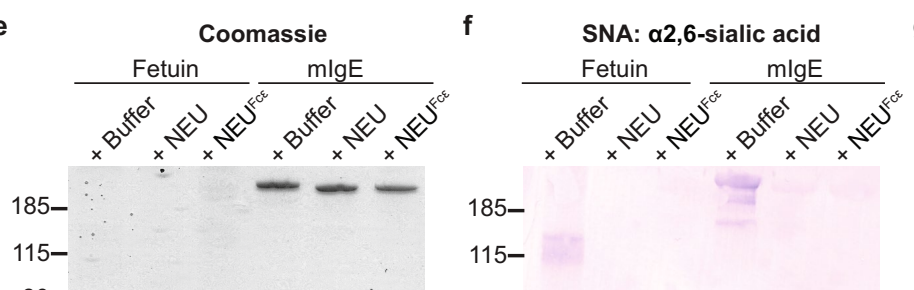

$80-$

$65-$

$50-$

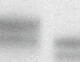

Extended Data Fig. $7 \mid$ PSA for IgE isotype controls and characterization of $\mathbf{N E U}^{\mathrm{Fc} \varepsilon}$.a, Temperature change following OVA-induced PSA in mice receiving DNP-specific ${ }^{\text {Sia }} \mathrm{mIgE}$ on day 0 , and then PBS, OVA-specific ${ }^{\text {Sia }} \mathrm{mIgE}$ or

OVA-specific ${ }^{\mathrm{As}} \mathrm{mIgE}$ isotype controls (from Fig. $3 \mathrm{e}$ ) on day $1 . n=4$ mice for all groups; two-way ANOVA with Tukey's multiple comparison test. b, Protein gel stain (left) and immunoblot (IB) for mIgE (right) of native and denatured $\mathrm{NEU}^{\mathrm{Fc \varepsilon}}$. c, Binding kinetics of analyte $\mathrm{NEU}^{\mathrm{Fc \varepsilon}}$ to ligand $\mathrm{hFc \varepsilon RI} \alpha$ on biosensor. Kinetics of analytes of threefold serial dilution from $26.2 \mathrm{nM}$ to $0.32 \mathrm{nM}$ were analysed. d, FACS analysis of surface-bound NEU ${ }^{\mathrm{Fc}}$ on LAD2 mast cells following $30 \mathrm{~min}$

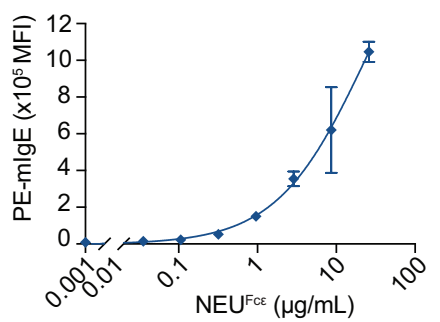

g

ECL: $\beta 1$,4-galactose

h

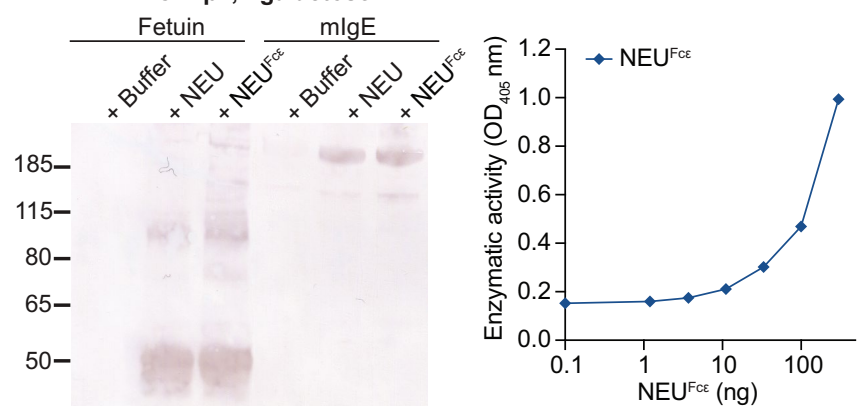

of sensitization at $37^{\circ} \mathrm{C} . n=3$ technical replicates per group, representative of two independent experiments. e-h, Neuraminidase activity of NEU ${ }^{\mathrm{Fc} \varepsilon}$ determined by digestion of mIgE or fetuin overnight $(\mathbf{e}-\mathbf{g})$, and detection of protein loading by Coomassie blue (e), terminal $\alpha 2,6$-sialic acid by SNA (f), and terminal galactose by Erythrina cristagalli lectin $(\mathrm{ECL})(\mathbf{g})$ or by the amount of substrate 2- $O$-( $p$-nitrophenyl)- $\alpha$-D- $N$-acetylneuraminic acid digested by NEU ${ }^{\mathrm{Fc} \varepsilon}$ in a colorimetric assay $(\mathbf{h} ; n=3$ technical replicates per group, representative of two independent experiments). Data are means \pm s.e.m. 
Extended Data Table 1| Patient demographic data

\begin{tabular}{|c|c|c|c|c|}
\hline Sample \# & Diagnosis & Gender & Age & Other Atopies* \\
\hline 73 & Allergic & $M$ & 22 & Yes \\
\hline 10 & Allergic & $\mathrm{F}$ & 25 & Yes \\
\hline 22 & Allergic & $\mathrm{F}$ & 19 & Yes \\
\hline 34 & Allergic & $\mathrm{F}$ & 30 & Yes \\
\hline 51 & Allergic & $\mathrm{F}$ & 15 & Yes \\
\hline 60 & Allergic & $\mathrm{F}$ & 40 & Yes \\
\hline 61 & Allergic & $\mathrm{F}$ & 27 & Yes \\
\hline 67 & Allergic & $\mathrm{F}$ & 52 & Yes \\
\hline 84 & Allergic & $M$ & 22 & Yes \\
\hline 97 & Allergic & $\mathrm{F}$ & 36 & Yes \\
\hline 24 & Allergic & $M$ & 36 & Yes \\
\hline 33 & Allergic & $\mathrm{F}$ & 30 & Yes \\
\hline 34 & Allergic & $\mathrm{F}$ & 16 & Yes \\
\hline 69 & Allergic & $M$ & 15 & Yes \\
\hline 80 & Allergic & $\mathrm{F}$ & 8 & Yes \\
\hline 95 & Allergic & $M$ & 8 & Yes \\
\hline 97 & Allergic & $\mathrm{F}$ & 36 & Yes \\
\hline 100 & Allergic & $\mathrm{F}$ & 22 & Yes \\
\hline 105 & Allergic & $\mathrm{F}$ & 22 & Yes \\
\hline 111 & Allergic & $\mathrm{F}$ & 22 & Yes \\
\hline 106 & Allergic & $\mathrm{F}$ & 32 & Yes \\
\hline 149 & Non-atopic & $M$ & 27 & No \\
\hline 349 & Non-atopic & $\mathrm{F}$ & 35 & No \\
\hline 241 & Non-atopic & $M$ & 29 & No \\
\hline 528 & Non-atopic & $M$ & 38 & No \\
\hline 53208 & Non-atopic & $M$ & 36 & No \\
\hline 53209 & Non-atopic & $M$ & 37 & No \\
\hline 53210 & Non-atopic & $M$ & 39 & No \\
\hline 53211 & Non-atopic & $\mathrm{F}$ & 31 & No \\
\hline 53195 & Non-atopic & $M$ & 60 & No \\
\hline 57543 & Non-atopic & $M$ & 69 & No \\
\hline 57544 & Non-atopic & $\mathrm{F}$ & 27 & No \\
\hline 57546 & Non-atopic & $M$ & 22 & No \\
\hline 57699 & Non-atopic & $M$ & 58 & No \\
\hline 57713 & Non-atopic & $M$ & 32 & No \\
\hline 57714 & Non-atopic & $M$ & 28 & \\
\hline 56986 & Non-atopic & $M$ & 29 & \\
\hline 56988 & Non-atopic & $\mathrm{F}$ & 50 & \\
\hline 57527 & Non-atopic & $\mathrm{F}$ & 29 & \\
\hline
\end{tabular}


Extended Data Table 2 | Targeted mass list for IgE glycopetides

\begin{tabular}{|c|c|c|c|c|c|c|}
\hline Mass [m/z] & CS [z] & Polarity & Start [min] & End [min] & $(\mathrm{N}) \mathrm{CE}$ & Comment \\
\hline 1197.84000 & 3 & Positive & 23.00 & 30.00 & 27 & $\operatorname{lgE} N 140 \mathrm{G} 2 \mathrm{~F}$ \\
\hline 1295.22000 & 3 & Positive & 28.00 & 34.00 & 27 & IgE N140 A1F \\
\hline 1265.54000 & 3 & Positive & 25.00 & 33.00 & 27 & IgE N140 G2F+BglcNAc \\
\hline 1362.91000 & 3 & Positive & 29.00 & 34.00 & 27 & IgE N140 A1F+BGIcNAc \\
\hline 1391.91000 & 3 & Positive & 32.00 & 37.00 & 27 & $\lg E \mathrm{~N} 140 \mathrm{~A} 2 \mathrm{~F}$ \\
\hline 1459.94000 & 3 & Positive & 32.00 & 37.00 & 27 & IgE N140 A2F+BglcNAc \\
\hline 1416.94000 & 3 & Positive & 28.00 & 34.00 & 27 & IgE N140 A1F+LAcNAc \\
\hline 1513.97000 & 3 & Positive & 32.00 & 37.00 & 27 & $\lg E \mathrm{~N} 140 \mathrm{~A} 2 \mathrm{~F}+\mathrm{LacNAc}$ \\
\hline 1319.57000 & 3 & Positive & 23.00 & 30.00 & 27 & IgE N140 G2F+LacNAc \\
\hline 922.70000 & 3 & Positive & 30.00 & 34.00 & 27 & $\lg E$ N168 G2F \\
\hline 990.40000 & 3 & Positive & 30.00 & 34.00 & 27 & IgE N168 G2F+BGlcNAc \\
\hline 1019.73000 & 3 & Positive & 36.00 & 40.00 & 27 & $\lg E \mathrm{~N} 168 \mathrm{~A} 1 \mathrm{~F}$ \\
\hline 1087.42000 & 3 & Positive & 36.00 & 40.00 & 27 & IgE N168 A1F+BGIcNAc \\
\hline 1184.45000 & 3 & Positive & 42.00 & 50.00 & 27 & IgE N168 A2F+BGIcNAc \\
\hline 1141.45000 & 3 & Positive & 36.00 & 40.00 & 27 & IgE N168 A1F+LAcNAc \\
\hline 1238.48000 & 3 & Positive & 42.00 & 50.00 & 27 & IgE N168 A2F+LAcNAc \\
\hline 1044.43000 & 3 & Positive & 30.00 & 34.00 & 27 & $\operatorname{lgE} N 168 \mathrm{G} 2 \mathrm{~F}+\mathrm{LAcNAc}$ \\
\hline 501.80000 & 2 & Positive & 45.00 & 55.00 & 27 & IgE N265 Agly \\
\hline 1337.20000 & 3 & Positive & 65.00 & 75.00 & 27 & $\lg E$ N265 A3F \\
\hline 992.10000 & 3 & Positive & 35.00 & 55.00 & 27 & $\lg$ E N265 G2F+GlcNAc \\
\hline 1118.50000 & 3 & Positive & 60.00 & 65.00 & 27 & $\lg E$ N265 A2F \\
\hline 1186.20000 & 3 & Positive & 60.00 & 65.00 & 27 & IgE N265 A2F+GlcNAc \\
\hline 1089.10000 & 3 & Positive & 52.00 & 58.00 & 27 & $\operatorname{lgE}$ N265 A1F+GlcNAc \\
\hline 924.40000 & 3 & Positive & 35.00 & 55.00 & 27 & $\lg E$ N265 G2F \\
\hline 1021.40000 & 3 & Positive & 52.00 & 58.00 & 27 & $\lg E$ N265 A1F \\
\hline 1143.40000 & 3 & Positive & 52.00 & 58.00 & 27 & IgE N265 A1F+LacNAc \\
\hline 1240.50000 & 3 & Positive & 60.00 & 65.00 & 27 & IgE N265 A2F+LacNAc \\
\hline 905.40000 & 4 & Positive & 27.00 & 32.00 & 27 & $\mathrm{~N} 218 \mathrm{~A} 1 \mathrm{~F}$ \\
\hline 883.10000 & 4 & Positive & 24.00 & 30.00 & 27 & $\mathrm{~N} 218 \mathrm{G} 2 \mathrm{~F}+\mathrm{GlcNAc}$ \\
\hline 1231.50000 & 3 & Positive & 23.00 & 30.00 & 27 & N218 G3F \\
\hline 519.60000 & 3 & Positive & 39.00 & 55.00 & 27 & Agly N218 \\
\hline 1029.00000 & 4 & Positive & 48.00 & 63.00 & 27 & $\mathrm{~N} 218 \mathrm{~A} 2 \mathrm{~F}+\mathrm{GlcNAC}$ \\
\hline 1142.20000 & 4 & Positive & 35.00 & 45.00 & 27 & N218 A3F \\
\hline 1123.15000 & 3 & Positive & 24.00 & 30.00 & 27 & $\mathrm{~N} 218 \mathrm{G} 1 \mathrm{~F}+\mathrm{GICNAC}$ \\
\hline 1069.10000 & 4 & Positive & 30.00 & 38.00 & 27 & $\mathrm{~N} 218 \mathrm{~A} 2 \mathrm{~F}+\mathrm{LacNAc}$ \\
\hline 956.20000 & 4 & Positive & 27.00 & 33.00 & 27 & $\mathrm{~N} 218 \mathrm{~A} 1 \mathrm{~F}+\mathrm{GlcNAC}$ \\
\hline 996.70000 & 4 & Positive & 27.00 & 33.00 & 27 & N218 A1F+LacNAc \\
\hline 1109.13000 & 3 & Positive & 24.00 & 30.00 & 27 & $\mathrm{~N} 218 \mathrm{G} 2 \mathrm{~F}$ \\
\hline 978.20000 & 4 & Positive & 30.00 & 38.00 & 27 & $\mathrm{~N} 218 \mathrm{~A} 2 \mathrm{~F}$ \\
\hline 1002.80000 & 3 & Positive & 30.00 & 37.00 & 27 & N371 G2F+GIcNAc \\
\hline 1099.80000 & 3 & Positive & 35.00 & 40.00 & 27 & N371 A1F+GIcNAc \\
\hline 1197.10000 & 3 & Positive & 40.00 & 50.00 & 27 & N371 A2F+GlcnAc \\
\hline 948.80000 & 3 & Positive & 30.00 & 38.00 & 27 & N371 G1F+GIcNAc \\
\hline 1153.80000 & 3 & Positive & 35.00 & 40.00 & 27 & N371 A1F+LacNAc \\
\hline 1032.80000 & 3 & Positive & 34.00 & 39.00 & 27 & N371 A1F \\
\hline 1045.80000 & 3 & Positive & 35.00 & 41.00 & 27 & $\mathrm{~N} 371 \mathrm{G} 1 \mathrm{~F}+\mathrm{GlcNAc}+\mathrm{NeuAc}$ \\
\hline 1129.80000 & 3 & Positive & 40.00 & 50.00 & 27 & N371 A2F \\
\hline 935.10000 & 3 & Positive & 30.00 & 35.00 & 27 & N371 G2F+GIcNAc \\
\hline 1056.80000 & 3 & Positive & 30.00 & 35.00 & 27 & N371 G3F \\
\hline 517.30000 & 2 & Positive & 30.00 & 38.00 & 27 & N371 Agly \\
\hline 912.10000 & 3 & Positive & 34.00 & 40.00 & 27 & N394 HM5 \\
\hline 966.10000 & 3 & Positive & 34.00 & 40.00 & 27 & N394 HM6 \\
\hline 1020.10000 & 3 & Positive & 34.00 & 40.00 & 27 & N394 HM7 \\
\hline 1074.20000 & 3 & Positive & 34.00 & 40.00 & 27 & N394 HM8 \\
\hline 1128.20000 & 3 & Positive & 34.00 & 40.00 & 27 & N394 HM9 \\
\hline 1071.40000 & 3 & Positive & 38.00 & 45.00 & 27 & N394 A1F-LACNAC \\
\hline 1179.50000 & 3 & Positive & 38.00 & 45.00 & 27 & N394 $3,6,1,1,0$ \\
\hline 1130.50000 & 3 & Positive & 38.00 & 45.00 & 27 & N394 3,6,0,1,0 \\
\hline
\end{tabular}

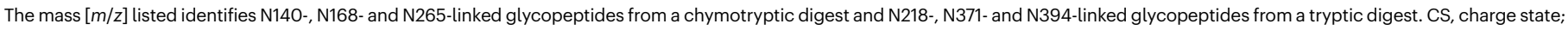
(N)CE, normalized collision energy. 
Extended Data Table $3 \mid$ Pertinent information regarding commercial antibody reagents

\begin{tabular}{|c|c|c|c|c|c|}
\hline FACS assay & Target & Clone & Fluorochromes & Vendor & Dilution \\
\hline \multirow{6}{*}{$\begin{array}{l}\text { IgE loading on mouse skin } \\
\text { mast cells }\end{array}$} & Mouse CD45 & $30-F 11$ & APC/Cyanine7 & Biolegend & $1: 400$ \\
\hline & Mouse/human CD11b & $\mathrm{M} 1 / 70$ & PerCP/Cyanine5.5 & Biolegend & $1: 100$ \\
\hline & Mouse CD11c & N418 & FITC & Biolegend & $1: 100$ \\
\hline & $\begin{array}{c}\text { Mouse Ly-6G/Ly-6C } \\
(\mathrm{Gr}-1)\end{array}$ & RB6-8C5 & FITC & Biolegend & $1: 100$ \\
\hline & Mouse CD117 (c-Kit) & 2B8 & APC & Biolegend & $1: 100$ \\
\hline & Mouse IgE & RME-1 & PE & Biolegend & $1: 100$ \\
\hline \multirow{3}{*}{$\begin{array}{l}\text { IgE loading on human LAD2 } \\
\text { cells }\end{array}$} & Human CD117 (c-kit) & 104D2 & PE & Biolegend & $1: 400$ \\
\hline & Ovalbumin & & A647 & Invitrogen & $1: 400$ of $2 \mathrm{mg} / \mathrm{mL}$ stock \\
\hline & Human IgE & MHE-18 & APC & Biolegend & $1: 400$ \\
\hline \multirow{6}{*}{$\begin{array}{l}\text { Phenotype staining for human } \\
\text { mast cells }\end{array}$} & Human HLA-DR & L243 & PE/Cy7 & Biolegend & $1: 35$ \\
\hline & Human CD123 & $6 \mathrm{H} 6$ & PE & Biolegend & $1: 30$ \\
\hline & Human CD63 & H5C6 & FITC & Biolegend & $1: 30$ \\
\hline & Human CD117 (c-kit) & 104D2 & APC & Biolegend & $1: 400$ \\
\hline & Human CD45 & HI30 & FITC & Biolegend & $1: 100$ \\
\hline & Human FceRla & AER-37 (CRA-1) & PE & Biolegend & $1: 400$ \\
\hline General & Viability & & eFluor 450 & eBioscience & $1: 500$ \\
\hline ELISA assay & Target & Catalog \# & Conjugation & Vendor & Dilution \\
\hline \multirow{2}{*}{ Mouse IgE ELISA } & $\mathrm{mlgE}$ & A90-115A & No & Bethyl & $1: 200$ \\
\hline & $\mathrm{mlg} E$ & A90-115P & HRP & Bethyl & $1: 30,000$ \\
\hline \multirow{2}{*}{ Human IgE ELISA } & hlgE & $A 80-108 A$ & No & Bethyl & $1: 200$ \\
\hline & hlgE & A80-108P & HRP & Bethyl & $1: 30,000$ \\
\hline Immunoblotting & Target & Catalog \# & Species/conjugation & Vendor & Dilution \\
\hline \multirow{2}{*}{ Immunoblotting for Syk } & Phospho-Syk & 2701 & Rabbit & Cell Signaling Technology & 1:2000 \\
\hline & Total & 2712 & Rabbit & Cell Signaling Technology & $1: 2000$ \\
\hline Secondary antibody & Rabbit IgG & W4011 & HRP & Promega & $1: 30,000$ \\
\hline Immunoblotting for Actin & Actin & sc-47778 HRP & HRP & Santa Cruz Biotechnology & $1: 50,000$ \\
\hline Passive Anaphylaxis & Species & Clone & Antigen specificity & Vendor & \\
\hline $\lg \mathrm{E}$ & Mouse & SPE-7 & dinitrophenyl (DNP) & Sigma-Aldrich & \\
\hline $\lg E$ & Mouse & MEA-36 & Trinitrophenyl (TNP) & Biolegend & \\
\hline
\end{tabular}




\section{natureresearch}

\section{Reporting Summary}

Nature Research wishes to improve the reproducibility of the work that we publish. This form provides structure for consistency and transparency in reporting. For further information on Nature Research policies, seeAuthors \& Referees and theEditorial Policy Checklist.

\section{Statistics}

For all statistical analyses, confirm that the following items are present in the figure legend, table legend, main text, or Methods section.

n/a Confirmed

$\boldsymbol{x}$ The exact sample size $(n)$ for each experimental group/condition, given as a discrete number and unit of measurement

x A statement on whether measurements were taken from distinct samples or whether the same sample was measured repeatedly

The statistical test(s) used AND whether they are one- or two-sided

Only common tests should be described solely by name; describe more complex techniques in the Methods section.

$\mathbf{x} \square$ A description of all covariates tested

$\boldsymbol{x}$ A description of any assumptions or corrections, such as tests of normality and adjustment for multiple comparisons

x A full description of the statistical parameters including central tendency (e.g. means) or other basic estimates (e.g. regression coefficient)

$\boldsymbol{x}$ AND variation (e.g. standard deviation) or associated estimates of uncertainty (e.g. confidence intervals)

For null hypothesis testing, the test statistic (e.g. $F, t, r$ ) with confidence intervals, effect sizes, degrees of freedom and $P$ value noted

- Give $P$ values as exact values whenever suitable.

$\mathbf{x} \square$ For Bayesian analysis, information on the choice of priors and Markov chain Monte Carlo settings

$\mathbf{x} \square$ For hierarchical and complex designs, identification of the appropriate level for tests and full reporting of outcomes

$\boldsymbol{x} \square$ Estimates of effect sizes (e.g. Cohen's $d$, Pearson's $r$ ), indicating how they were calculated

Our web collection on statistics for biologists contains articles on many of the points above.

\section{Software and code}

Policy information about availability of computer code

Data collection FACS samples were acquired by an LSR II flow cytometer (BD Biosciences) or CytoFLEX (Beckman Coulter). The absorbance at $450 \mathrm{~nm}$ for ELISA, $405 \mathrm{~nm}$ for mast cell degranulation and sialidase activity assays and $595 \mathrm{~nm}$ for blue dye of mouse ears were measured by Molecular Devices SpectraMax Plus 384 microplate reader. Site-specific glycosylation was determined by nano LC-MS/MS using a Thermo EasySpray C18 nLC followed by a Thermo QExactive mass spectrometer. Rectal temperature was measured by a rectal microprobe thermometer (Physitemp). Binding interaction between analyte and ligand was acquired by Octet System Data Acquisition Software.

Data analysis Data was analysed by GraphPad Prism version 8 and FlowJo version 10. For binding kinetic parameters, analyses were performed by Octet data analysis software 10.0.

For manuscripts utilizing custom algorithms or software that are central to the research but not yet described in published literature, software must be made available to editors/reviewers. We strongly encourage code deposition in a community repository (e.g. GitHub). See the Nature Research guidelines for submitting code \& software for further information.

\section{Data}

Policy information about availability of data

All manuscripts must include a data availability statement. This statement should provide the following information, where applicable:

- Accession codes, unique identifiers, or web links for publicly available datasets

- A list of figures that have associated raw data

- A description of any restrictions on data availability

Source data tables are provided for Figs. 1-3 and Extended Data Figs. 1, 4-7. Full scans of all uncropped protein gel stains, lectin or western blots with size marker indication presented in this manuscript are shown in the Supplementary Information. All other data supporting the findings in this study are available from the corresponding author upon request. 


\section{Field-specific reporting}

Please select the one below that is the best fit for your research. If you are not sure, read the appropriate sections before making your selection.
$\boldsymbol{x}$ Life sciences
Behavioural \& social sciences
Ecological, evolutionary \& environmental sciences

For a reference copy of the document with all sections, see nature.com/documents/nr-reporting-summary-flat.pdf

\section{Life sciences study design}

All studies must disclose on these points even when the disclosure is negative.

$\begin{array}{ll}\text { Sample size } & \begin{array}{l}\text { No statistical method was used to determine sample size. For murine experiments, we generally use 4-5 mice per experimental group and } \\ \text { have found that performing the types of experiments described in this study with 4-5 mice per experimental group is management and } \\ \text { provide robust data with statistically significant differences between the groups. }\end{array}\end{array}$

Data exclusions No data was excluded for all experiments.

Replication All findings in this study were reliably reproduced as indicated in the figure legends. For in vitro studies, the samples were in duplicate or triplicate and performed at least 3 independent times to confirm the finding. For murine studies, 4-5 mice per experimental group is generally used and repeated at least 2-3 independent times. When possible, the finding was verified using IgE of a different antigen specificity.

Randomization For all murine experiments, mice were randomly assigned into a control or treatment group.

Blinding The measurement of rectal temperature in mice upon antigen challenge in passive systemic and food anaphylaxis was performed in a blinded manner.

\section{Reporting for specific materials, systems and methods}

We require information from authors about some types of materials, experimental systems and methods used in many studies. Here, indicate whether each material, system or method listed is relevant to your study. If you are not sure if a list item applies to your research, read the appropriate section before selecting a response.

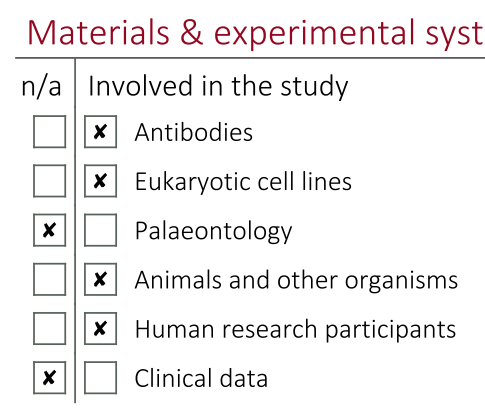

Methods $\mathrm{n} / \mathrm{a}$ Involved in the study

$\boldsymbol{x}$ ChIP-seq

$\square \quad x$ Flow cytometry

$\boldsymbol{x} \quad \square$ MRI-based neuroimaging

\section{Antibodies}

Antibodies used

For antibodies used to detect IgE loading on mouse skin mast cells were all purchased from Biolegend:

Anti-mouse CD45 (clone: 30-F11, fluorochrome: APC/Cyanine7, Cat\#: 103116, lot number: B290026, dilution: 1:400) Anti-mouse CD11b (clone: M1/70, fluorochrome: PerCP/Cyanine5.5, Cat\#: 101228, lot number: B283049, dilution: 1:100) Anti-mouse CD11C (clone: N418, fluorochrome: FITC, Cat\#: 117306, lot number: B277030, dilution: 1:100) Anti-mouse Ly-6G/Ly-6C (Gr-1) (clone: RB6-8C5, fluorochrome: FITC, Cat\#: 108406, lot number: B281017, dilution: 1:100) Anti-mouse CD117 (c-Kit) (clone: 2B8, fluorochrome: APC, Cat\#: 105812, lot number: B217855, dilution: 1:100) Anti-mouse IgE (clone: RME-1, fluorochrome: PE, Cat\#: 406908, lot number: B262647, dilution: 1:100)

For antibodies and reagents used to detect IgE loading on human LAD2 cells:

Anti-human CD117 (c-Kit) (clone: 104D2, fluorochrome: PE, Biolegend, Cat\#: 313204, lot number: B213235, dilution: 1:400) Anti-human IgE (clone: MHE-18, fluorochrome: APC, Biolegend, Cat\#: 325508, lot number: B189349, dilution: 1:400) Ovalbumin-A647 (Invitrogen, Cat\#: O34784, lot number: 1579032, dilution: 1:400 of 2 mg/mL stock)

All antibodies used in basophil activation tests were purchased from Biolegend:

Anti-human HLA-DR (clone: L243, fluorochrome: PE/Cy7, Cat\#: 307616, lot number: B219674, dilution: 1:35)

Anti-human CD123 (clone: 6H6, fluorochrome: PE, Cat\#: 306006, lot number: B240987, dilution: 1:30)

Anti-human CD63 (clone: H5C6, fluorochrome: FITC, Cat\#: 353005, lot number: B191023, dilution: 1:30) 


\begin{abstract}
All antibodies used for phenotypic staining of human mast cells were purchased from Biolegend:
Anti-human CD117 (c-Kit) (clone: 104D2, fluorochrome: APC, Cat\#: 313206, lot number: B179745, dilution: 1:400)

Anti-human CD45 (clone: HI30, fluorochrome: FITC, Cat\#: 304006, lot number: B233140, dilution: 1:100)

Anti-human FceRIa (clone: AER-37 (CRA-1), fluorochrome: PE, Cat\#: 334609, lot number: B190666, dilution: 1:400)

To detect the cell viability: Fixable Viability Dye eFluor ${ }^{\mathrm{TM}} 450$ (eBioscience, Cat\#: 65-0863-14, lot number: 2143488, dilution: 1:500)
\end{abstract}

For antibodies used to detect IgE in ELISA:

Goat polyclonal anti-mouse IgE Antibody (Bethyl Laboratories, Catalog \# A90-115A, lot number: A90-115A-26, dilution: 1:200) Goat polyclonal anti-mouse IgE Antibody, HRP Conjugated (Bethyl Laboratories, Catalog \# A90-115P, lot number: A90-115P-32, dilution: 1:30,000)

Goat polyclonal anti-human IgE Antibody (Bethyl Laboratories, Catalog \# A80-108A, lot number: A80-108A-16, dilution: 1:200) Goat polyclonal anti-human IgE Antibody, HRP Conjugated (Bethyl Laboratories, Catalog \# A80-108P, lot number: A80-108P-29, dilution: 1:30,000)

For antibodies used in immunoblotting:

Mouse anti- $\beta$-Actin Antibody (C4), HRP Conjugated (Santa Cruz Biotechnology, Catalog \# sc-47778 HRP, lot number: J1912, dilution: $1: 50,000)$

Anti-Rabbit IgG (H+L), HRP Conjugated (Promega, Catalog \#W4011, lot number: 0000037532, dilution: 1:30,000) Rabbit anti-Phospho-Syk (Tyr352) Antibody (Cell Signaling Technology, Product \#2701, lot number: 10, dilution: 1:2000) Rabbit anti-Syk Antibody (Cell Signaling Technology, Product \#2712, lot number: 16, dilution: 1:2000)

For mlgE antibodies used in passive anaphylaxis studies:

Monoclonal mIgE specific for dinitrophenyl (DNP, clone SPE-7; Sigma-Aldrich, Cat\#: D8406, lot number: 018M4805V) Monoclonal mlgE specific for trinitrophenyl (TNP, clone MEA-36; Biolegend, Cat\#: 401701, lot number: B269037)

Validation

All antibodies were well-established clones and commercially available from Biolegend, Sigma-Aldrich, Cell Signaling Technology, Promega, Santa Cruz Biotechnology, Bethyl Laboratories, eBioscience. Unless otherwise noted, all antibodies were used at concentrations recommended by the manufacturer for the relevant assays. The validation data for the antibodies and product citations are provided on the manufacturer's website.

\title{
Eukaryotic cell lines
}

Policy information about cell lines

Cell line source(s)

Human LAD2 mast cells were obtained from Dr. Metcalfe (NIAID, NIH) that generated the cell line and Expi293F Cells were purchased from ThermoFisher Scientific.

Authentication

Cells lines used in this study were not authenticated.

Mycoplasma contamination

Cell lines used in this study were not tested for mycoplasma contamination.

Commonly misidentified lines

(See ICLAC register)

Cell lines used in this study were not listed in The ICLAC Register of Misidentified Cell Lines.

\section{Animals and other organisms}

Policy information about studies involving animals; ARRIVE guidelines recommended for reporting animal research

Laboratory animals

Five- to six-week-old female BALB/c mice were purchased from the Jackson Laboratory and used in the studies.

Wild animals

The study did not involve wild animals.

Field-collected samples

The study did not involve samples collected from the field.

Ethics oversight

All mice were housed in specific pathogen-free conditions according to the National Institutes of Health $(\mathrm{NIH})$, and all animal experiments were conducted under protocols approved by the MGH Institutional Animal Care and Use Committee.

Note that full information on the approval of the study protocol must also be provided in the manuscript.

\section{Human research participants}

Policy information about studies involving human research participants

Population characteristics 18 males, 21 females, aged 15-60 (please see Extended Data Table 1). 

parents a recruitment letter. The letter included contact information for study staff so the subject could opt in to participation. If no contact was received, the study staff contacted the subject, discussed the study, and conducted a telephone screen. Patients were confirmed to have peanut allergy by the presence of specific IgE to peanuts (serum peanut-specific IgE [CAP-FEIA $>10 \mathrm{kU} / \mathrm{L}]$ ) and a recent history (within 12 months) of objective clinical symptoms within 60 minutes after the ingestion of peanuts.

The parents and patient were educated about the study and informed consent was obtained in accordance with IRB policy by referring allergists or by the study investigator, with at least 48 hours prior to enrollment and randomization. Minors between the ages of 7 and 13 were given the Youth Assent Form to sign; minors from ages 14 to 17 signed the parental consent form. Subjects enrolled as minors were provided an adult consent form for signature when they reached age 18 and were reconsented. (Extended Data Table 1).

IRB-approved non-atopic adults were recruited (Research Blood Components, Boston, MA) on the basis of self-identification as non-allergic donors. Non-atopy was confirmed by clinical history, and allergen-specific IgE screening.

Ethics oversight

MGH IRB Human Subjects Assurance Number 00003136; Peanut Oral Immunotherapy: PNOIT2: Clinical Trials ID number NCT01750879

Note that full information on the approval of the study protocol must also be provided in the manuscript.

\section{Flow Cytometry}

\section{Plots}

Confirm that:

$\boldsymbol{x}$ The axis labels state the marker and fluorochrome used (e.g. CD4-FITC).

$\boldsymbol{x}$ The axis scales are clearly visible. Include numbers along axes only for bottom left plot of group (a 'group' is an analysis of identical markers).

x All plots are contour plots with outliers or pseudocolor plots.

$\boldsymbol{x}$ A numerical value for number of cells or percentage (with statistics) is provided.

\section{Methodology}

Sample preparation

Instrument

Software

Cell population abundance

\begin{abstract}
To prepare single cell suspensions from mouse ears, mouse ears were removed, separated into dorsal and ventral halves, and minced before incubation in buffer containing collagenase at $37^{\circ} \mathrm{C}$ for $1 \mathrm{~h}$ at $180 \mathrm{RPM}$. The digested sample was then subjected to disruption by Gentle MACS and filtered through cell strainer.
\end{abstract}

Buffy coats of human blood from healthy, de-identified, consenting donors were obtained from the MGH Blood Transfusion Service. Peripheral blood mononuclear cells (PBMCs) were separated from buffy coats by a density gradient centrifugation using Ficoll Paque Plus (GE Healthcare) and resuspended in 0.5\% BSA in RPMI 1640 Media (GE Healthcare). PBMCs were incubated for 2 min with ice-cold lactic acid buffer ( $13.4 \mathrm{mM}$ lactate, $140 \mathrm{mM} \mathrm{NaCl}, 5 \mathrm{mM} \mathrm{KCl}, \mathrm{pH} 3.9)$ to remove endogenous human IgE on the cell surface prior to neutralization by $12 \%$ Tris (pH 8). Cells were then washed and incubated 1 hour at $37^{\circ} \mathrm{C}$ with $1 \mu \mathrm{g}$ OVAspecific SiahlgE or AshlgE per $1 \times 106$ cells in basophil activation buffer (0.5\% BSA, $2 \mathrm{mM} \mathrm{CaCl} 2$ and $2 \mathrm{mM} \mathrm{MgCl} 2$ in RPMl 1640 Media). Sensitized cells were washed and resuspended in basophil activation buffer supplemented with $10 \mathrm{ng} / \mathrm{mL}$ human IL3 (Peprotech) prior to 30 min OVA activation. Activation was stopped by addition of ice-cold $0.2 \mathrm{M}$ EDTA in FACS buffer. Cells were washed and resuspended in FACS buffer prior to antibody staining (Extended Data Table 3) for activation marker (LAMP-3; CD63 +) on basophils (CD123+HLADR-).

Primary human mast cells were generated as previously described. Briefly, PBMC were separated from buffy coats as described above before isolation of CD34+ pluripotent hematopoietic cells by EasySepTM Human Whole Blood CD34 Positive Selection Kit \| (STEMCELL Technologies). CD34+ cells were cultured in StemPro-34 SFM medium (Life Technologies) supplemented with $2 \mathrm{mM}$ L-glutamine, $100 \mathrm{U} / \mathrm{ml}$ penicillin, $100 \mathrm{\mu g} / \mathrm{ml}$ streptomycin, $50 \mathrm{ng} / \mathrm{mL}$ recombinant human stem cell factor (Peprotech), $50 \mathrm{ng} / \mathrm{mL}$ human IL-6 (Peprotech), and with $10 \mathrm{ng} / \mathrm{mL}$ human IL-3 (Peprotech) in the first week. The cells were cultured in similar culture media but without human IL-3 after the first week to mature for 10 weeks. Cultured mast cells were confirmed by FACS staining of $\mathrm{CD} 45+, \mathrm{C}-\mathrm{KIT}+, \mathrm{FcERI}+$.

To enrich for native human IgE from serum, serum was treated with protein $G$ to deplete IgG before incubating with anti-human IgE conjugated agarose beads.

To generate recombinant OVA-specific mouse or human IgE, plasmids containing OVA-specific heavy and light chain were transiently co-transfected in Expi293F cells using Expi293 Expression System Kit. The cells expressing IgE were selected by 400 $\mu \mathrm{g} / \mathrm{mL} \mathrm{G418}$ and expanded to a larger scale production. OVA-specific IgE was purified from cell culture supernatant by OVAcoupled agarose beads.

FACS samples were acquired by an LSR II flow cytometer (BD Biosciences) or CytoFLEX (Beckman Coulter).

All data were analysed by GraphPad Prism version 8. FACS data were analysed by FlowJo version 10. 
To select mouse skin mast cells (Extended Data Fig. 5e), the cells were first gated on its viability followed by CD45+ expression. Within CD45+ population, cells with low expression of CD11b, CD11c, and GR1 (CD11b-CD11c-GR1-) were selected followed by gating on the population with high c-Kit (c-Kit+) expression.

To gate basophils (Extended Data Fig. 6c), singlet cells selected based on FSC-A/FSC-H were gated by the high expression of CD123 (CD123+) and low expression of HLADR (HLADR-).

$\mathbf{x}$ Tick this box to confirm that a figure exemplifying the gating strategy is provided in the Supplementary Information. 